\title{
Building Industry Reporting and Design for Sustainability (BIRDS) Tutorial for New Low-Energy Residential Database
}

Joshua Kneifel

Eric O'Rear

Priya Lavappa

This publication is available free of charge from: http://dx.doi.org/10.6028/NIST.TN.1919

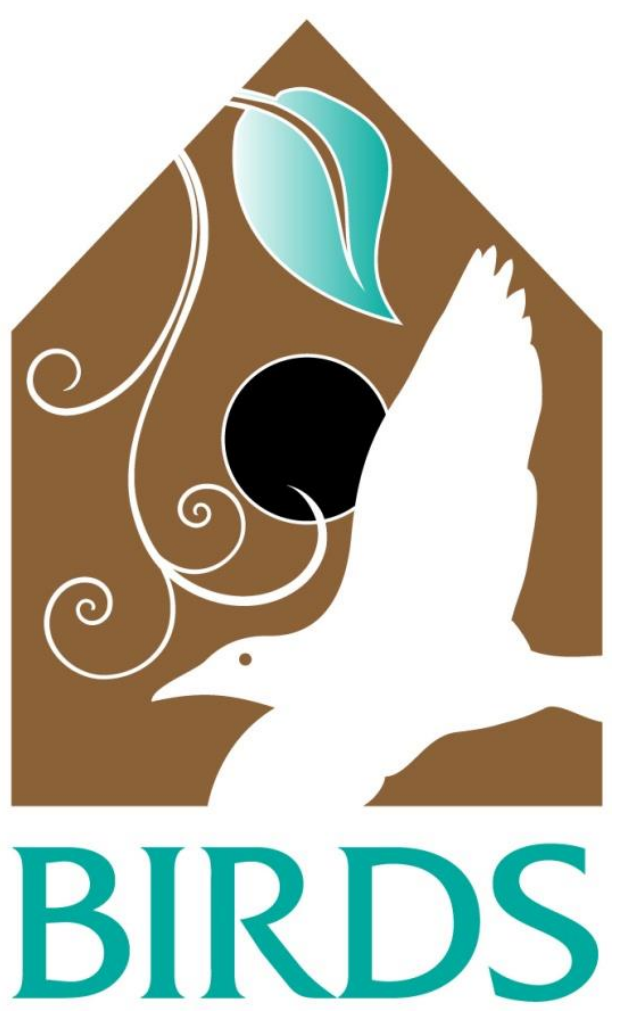



NIST Technical Note 1919

\title{
Building Industry Reporting and Design for Sustainability (BIRDS) Tutorial for New Low-Energy Residential Database
}

\author{
Joshua Kneifel \\ Eric O'Rear \\ Priya Lavappa \\ Applied Economics Office \\ Engineering Laboratory
}

This publication is available free of charge from:

http://dx.doi.org/10.6028/NIST.TN.1919

May 2016

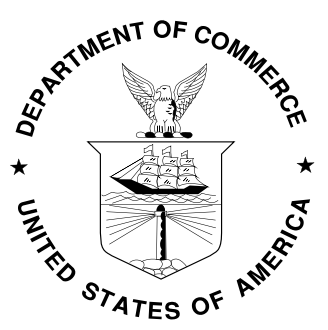

U.S. Department of Commerce Penny Pritzker, Secretary

National Institute of Standards and Technology

Willie May, Under Secretary of Commerce for Standards and Technology and Director 
Certain commercial entities, equipment, or materials may be identified in this document in order to describe an experimental procedure or concept adequately. Such identification is not intended to imply recommendation or endorsement by the National Institute of Standards and Technology, nor is it intended to imply that the entities, materials, or equipment are necessarily the best available for the purpose.

National Institute of Standards and Technology Technical Note 1919

Natl. Inst. Stand. Technol. Tech. Note 1919, 29 pages (May 2016)

http://dx.doi.org/10.6028/NIST.TN.1919

CODEN: NTNOEF 


\begin{abstract}
Building stakeholders need practical metrics, data, and tools to support decisions related to sustainable building designs, technologies, standards, and codes. The Engineering Laboratory of the National Institute of Standards and Technology (NIST) has addressed this high priority national need by extending its metrics and tools for sustainable building products, known as Building for Environmental and Economic Sustainability (BEES), to whole buildings. Whole building sustainability metrics have been developed based on innovative extensions to life-cycle assessment (LCA) and life-cycle costing (LCC) approaches involving whole building energy simulations. The measurement system evaluates the sustainability of both the materials and the energy used by buildings over time. It assesses the "carbon footprint" of buildings as well as 11 other environmental performance metrics, and integrates economic performance metrics to yield science-based measures of the business case for investment choices in high-performance green buildings.

Building Industry Reporting and Design for Sustainability (BIRDS) applies the new sustainability measurement system to an extensive whole building performance database NIST has compiled for this purpose. Based on the NIST Net Zero Energy Residential Test Facility (NZERTF), the BIRDS Low-Energy Residential building database includes energy, environmental, and cost measurements for 240000 residential building designs for Gaithersburg, MD for study period lengths ranging from 1 year to 40 years. Focusing on a single location allows for the consideration of incremental building energy efficiency measures, both those specified in most recent editions of International Energy Conservation Code (IECC) as well as those adopted in the NZERTF design that lead to net-zero energy performance. The sustainability performance of buildings designed to meet current energy codes can be compared to a number of alternative building designs to determine the impacts of improving building energy efficiency on overall sustainability performance. Additional options built into BIRDS v3.0 that were not included in previous versions include varying discount rates, home purchase financing, and quality of construction options.
\end{abstract}

This document is a tutorial to assist BIRDS users in understanding and using the BIRDS New Low-Energy Residential Buildings Database Web Interface, including detailed definitions for and explanation of the purpose of each input and output option.

\title{
Keywords
}

Building economics; economic analysis; life-cycle costing; life-cycle assessment; energy efficiency; low-energy buildings; residential buildings 


\section{Preface}

This documentation was developed by the Applied Economics Office (AEO) in the Engineering Laboratory (EL) at the National Institute of Standards and Technology (NIST). The BIRDS new low-energy residential database web interface is designed to assess the sustainability performance (energy, environmental, and cost impacts) of the adoption of new residential building designs. The intended audience is users of BIRDS, such as researchers and decision makers in the residential building sector, and others interested in building sustainability.

\section{Disclaimers}

The policy of the National Institute of Standards and Technology is to use metric units in all of its published materials. Because this report is intended for the U.S. construction industry that uses U.S. customary units, it is more practical to include U.S. customary units as well as metric units. Measurement values in this report are therefore stated in metric units first, followed by the corresponding values in U.S. customary units within parentheses. 


\section{Acknowledgements}

The authors wish to thank all those who contributed ideas and suggestions for this report. They include Mr. David Webb and Dr. Robert Chapman of EL's Applied Economics Office, Ms. Tania Ullah of EL's Energy and Environment Division, and Dr. Nicos S. Martys of EL's Materials and Structural Systems Division. A special thanks to the Industrial Ecology Research Services team of Shivira Tomar, Christine Chen, and Matthew Leighton for their superb technical support in developing whole-building environmental life-cycle assessments for BIRDS. Thanks go to researchers at the Institute for Software Integrated Systems of the School of Engineering at Vanderbilt University for assisting in generating and compiling the energy simulation results. Thanks goes to our industry contacts that were instrumental in advising on the assumptions used to develop the product-level life-cycle impact assessments. Thanks to Ms. Shannon Craig for assisting in developing the low-energy residential sustainability database. Finally, the many Beta testers of BIRDS v3.0 deserve special thanks for contributing suggestions leading to substantial improvements in the tool. 


\section{Author Information}

Joshua Kneifel

Economist

National Institute of Standards and Technology

Engineering Laboratory

100 Bureau Drive, Mailstop 8603

Gaithersburg, MD 208998603

Tel.: 301-975-6857

Email: joshua.kneifel@nist.gov

Eric G. O’Rear

Economist

National Institute of Standards and Technology

Engineering Laboratory

100 Bureau Drive, Mailstop 8603

Gaithersburg, MD 208998603

Tel.: 301-975-4570

Email: eric.orear@nist.gov

Priya Lavappa

Computer Specialist

National Institute of Standards and Technology

Engineering Laboratory

100 Bureau Drive, Mailstop 8603

Gaithersburg, MD 208998603

Tel.: 301-975-4522

Email: priya.lavappa@nist.gov 


\section{Contents}

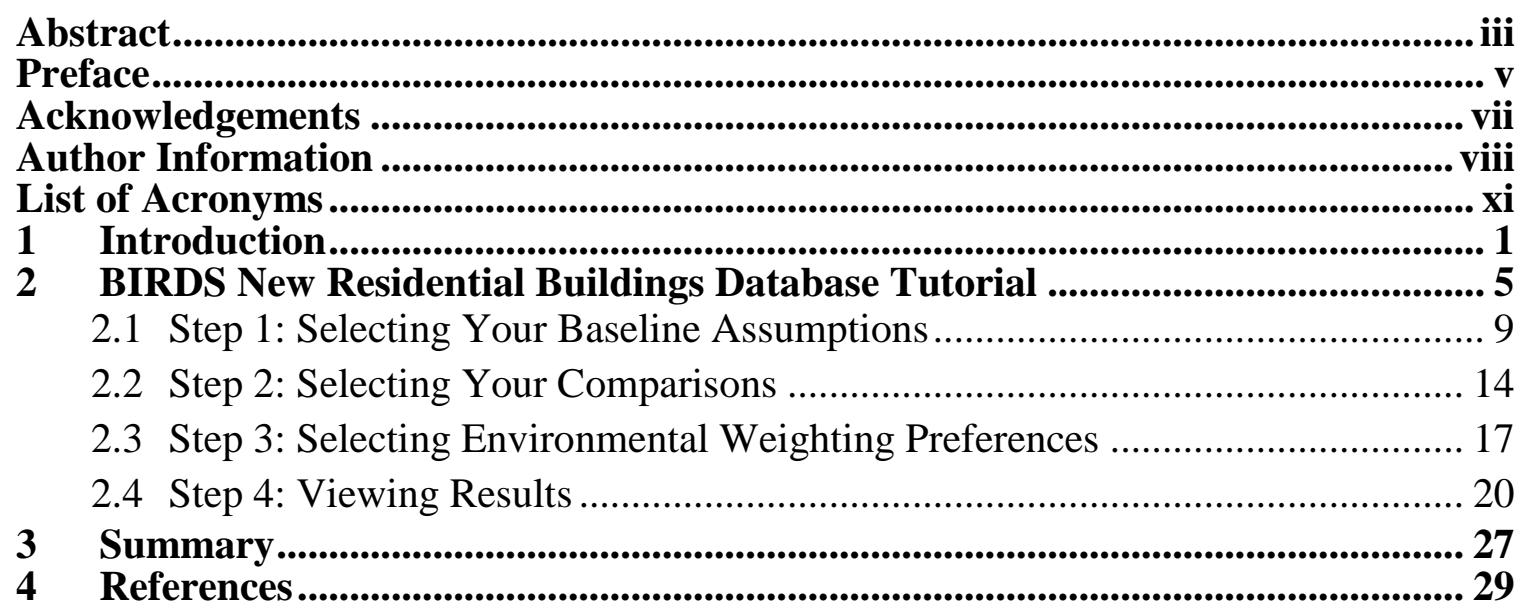

\section{List of Figures}

Figure 1-1 BIRDS Sustainability Framework.................................................................... 2

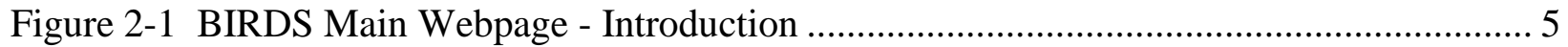

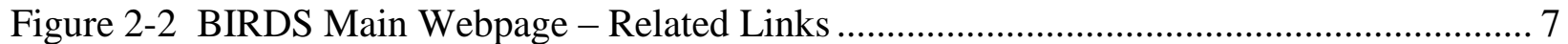

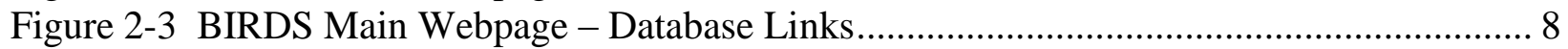

Figure 2-4 BIRDS Main Webpage - Start Analysis .............................................................. 8

Figure 2-5 BIRDS New Residential Interface - Initial View ................................................... 9

Figure 2-6 Baseline Assumptions - Analysis Assumptions ....................................................... 10

Figure 2-7 Baseline Assumptions -Building Components ……………................................. 12

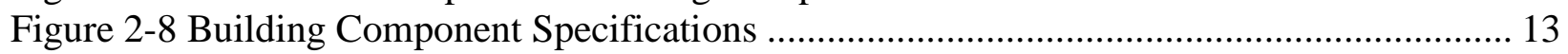

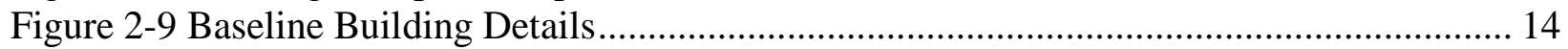

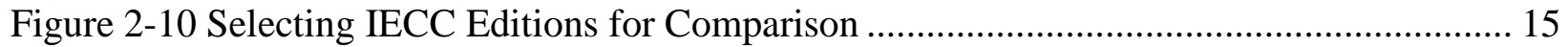

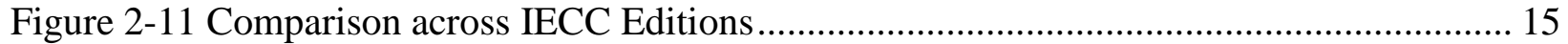

Figure 2-12 Selecting User-Defined Building Alternatives for Comparison …………................. 16

Figure 2-13 Selected Design Alternative to be compared to the Baseline ................................... 17

Figure 2-14 Selecting Environmental Weighting Preferences - Pre-defined Weighting Approach

Figure 2-15 Selecting Environmental Weighting Preferences - Custom Weighting ................... 19

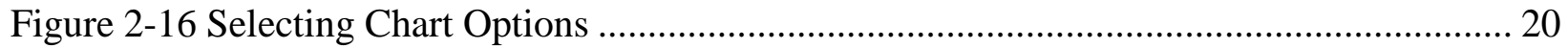

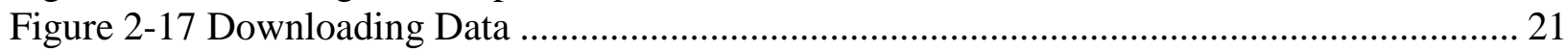

Figure 2-18 Life-Cycle Cost Graph by Wall Assembly for Baseline Assumptions ...................... 22

Figure 2-19 Operating Energy Graph by Wall Assembly for Baseline Assumptions .................. 24

Figure 2-20 Environmental Impact Score by Wall Assembly - for Baseline............................... 25

Figure 2-21 Global Warming Potential by Wall Assembly Structure - for Baseline Assumptions 


\section{List of Acronyms}

\section{Acronym Definition}

ACH50 air changes per hour at $50 \mathrm{~Pa}$

AEO Applied Economics Office

BEES Building for Environmental and Economic Sustainability

BIRDS Building Industry Reporting and Design for Sustainability

$\mathrm{CO} 2 \mathrm{e}$ cardon dioxide equivalent

EIS Environmental Impact Score

EL Engineering Laboratory

FAQ Frequently Asked Questions

HVAC Heating, Ventilation, and Air Conditioning

IECC International Energy Conservation Code

I-P Imperial units

LCA Life-Cycle Assessment

LCC Life-Cycle Cost

NIST National Institute of Standards and Technology

NZERTF Net-Zero Energy Residential Test Facility

PV Present Value

SHGC Solar Heat Gain Coefficient 


\section{Introduction}

A wave of interest in sustainability gathered momentum in 1992 with the Rio Earth Summit, during which the international community agreed upon a definition of sustainability, which is still cited one of the most cited to this day, in the Bruntland report: "meeting the needs of the present generation without compromising the ability of future generations to meet their own needs" (Brundtland Commission 1987). In the context of sustainable development, needs can be thought to include the often-conflicting goals of environmental quality, economic well-being, and social justice. While the intent of the 1992 summit was to initiate environmental and social progress, it seemed to have instead brought about greater debate over the inherent conflict between sustainability and economic development, which has continued up to today.

This conflict is particularly apparent within the construction industry. Frequently, well-intentioned green development plans are not executed for economic reasons, and economic development plans fail to materialize over concerns for the environment and public health. Thus, an integrated approach to sustainable construction - one that simultaneously considers both environmental and economic performance - lies at the heart of reconciling the conflict. For this reason, building stakeholders need practical metrics, data, and tools to support decisions related to sustainable building designs, technologies, standards, and codes that consider both the environmental protection and economic growth dimensions of sustainability.

The Engineering Laboratory (EL) of the National Institute of Standards and Technology (NIST) has addressed this high priority national need by extending its metrics and tools for sustainable building products, known as Building for Environmental and Economic Sustainability (BEES) (National Institute of Standards and Technology (NIST) 2010) at the whole building level to address building sustainability measurement in an integrated manner that considers complex interactions among building materials, energy technologies, and systems across dimensions of performance, scale, and time. Whole building sustainability metrics have been developed based on innovative extensions to life-cycle assessment (LCA) and life-cycle costing (LCC) approaches involving whole building energy simulations. The measurement system evaluates the sustainability of both the construction materials and the energy used by a building over time. It assesses the "carbon footprint" of buildings as well as 11 other environmental performance metrics, and integrates economic performance metrics to yield science-based measures of the business case for investment choices in high-performance green buildings. This approach does not consider the social equality dimension of sustainability due to the current lack of rigorous measurement methods.

Building Industry Reporting and Design for Sustainability (BIRDS) applies the new sustainability measurement system to an extensive whole building performance database NIST has compiled for this purpose (National Institute of Standards and Technology (NIST) 2014). The energy, environment, and cost data in BIRDS measure building operating energy use through detailed energy simulations, building materials use through life-cycle material 
inventories, and building costs over time. BIRDS v1.0 included energy, environmental, and cost measurements for 11 building prototypes in 228 cities for a total of 12540 new commercial and non low-rise residential building designs across all U.S. states for 9 study period lengths. See Lippiatt, Kneifel et al. (2013) for additional details. BIRDS v2.0 included both the commercial and residential database which included the energy, environmental, and cost measurements for 9120 residential buildings, covering 10 single family dwellings ( 5 one-story and 5 two-story of various conditioned floor area) in 228 cities for study period lengths ranging from 1 year to 40 years. See Kneifel and Lavappa (2015) for additional details related to the underlying assumptions, data sources, and approaches implemented to develop the BIRDS new residential database. All the variables shown in Figure 1-1 are accounted for in the BIRDS database.

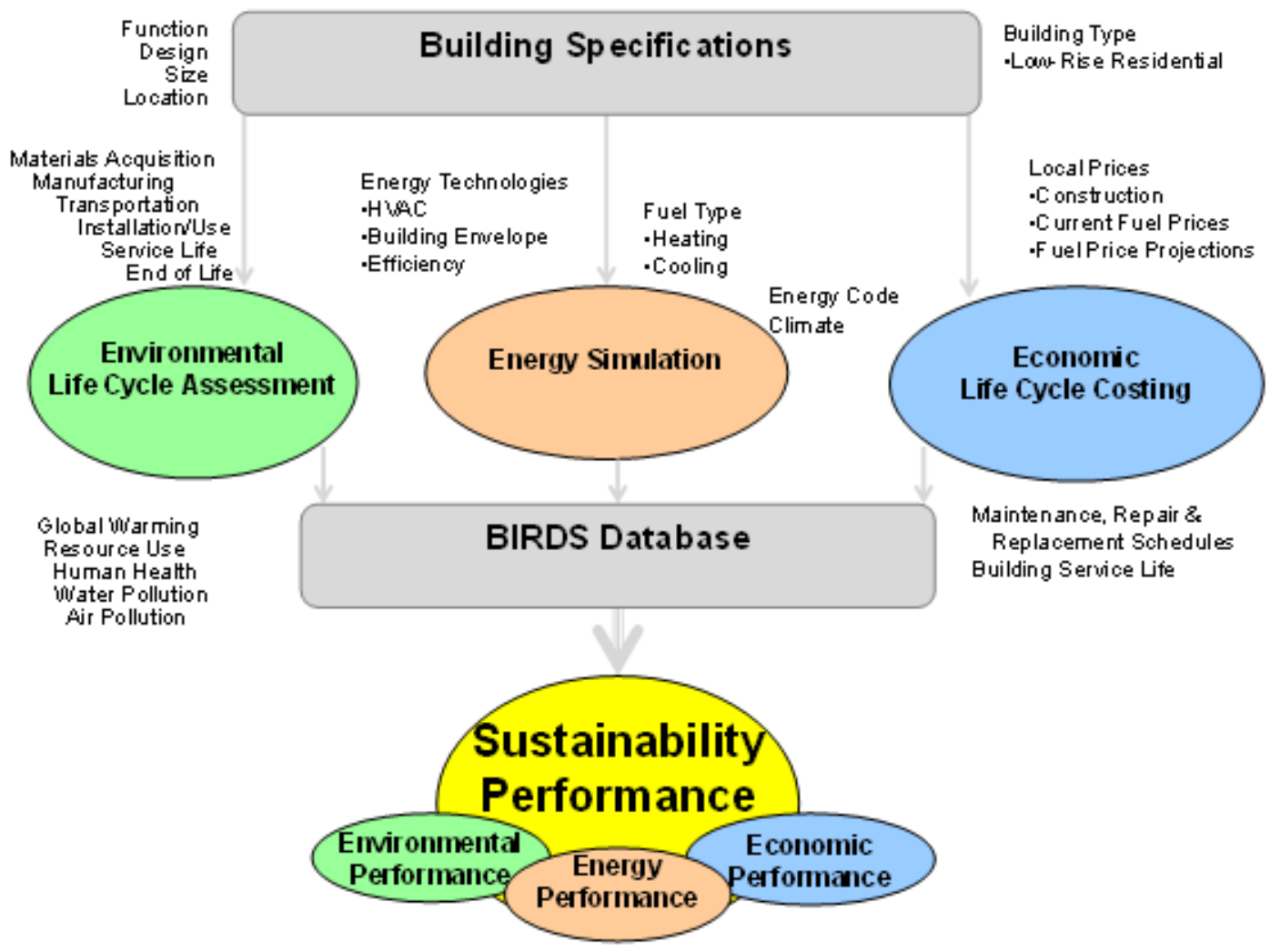

Figure 1-1 BIRDS Sustainability Framework

Similar to the previous databases, the low-energy residential database incorporated into BIRDS v3.0 includes the energy, environmental, and cost measurements. However, instead of considering locations across the country with minimal building design options, BIRDS v3.0 allows for detailed incremental energy efficiency measure analysis for a single location, 240000 residential building designs based on the NIST Net-Zero Energy Residential Test Facility (NZERTF) specifications and varying requirements across International Energy Conservation Code (IECC) editions. ${ }^{1}$ Again, study period lengths from 1 year to 40 years are included in the

\footnotetext{
${ }^{1}$ BIRDS has been designed to allow for additional locations to be incorporated in future versions.
} 
low-energy residential database. The sustainability performance of buildings designed to meet current energy codes can be compared to a number of alternative building designs to determine the impacts of improving building energy efficiency as well as varying the investor time horizon and other assumptions on overall sustainability performance. 


\section{BIRDS New Residential Buildings Database Tutorial}

A user begins on the BIRDS main webpage, which is a "one-stop shop" for information related to BIRDS. In the center of the webpage, there is an introduction to the purpose and capabilities of the BIRDS databases (highlighted in Figure 2-1).

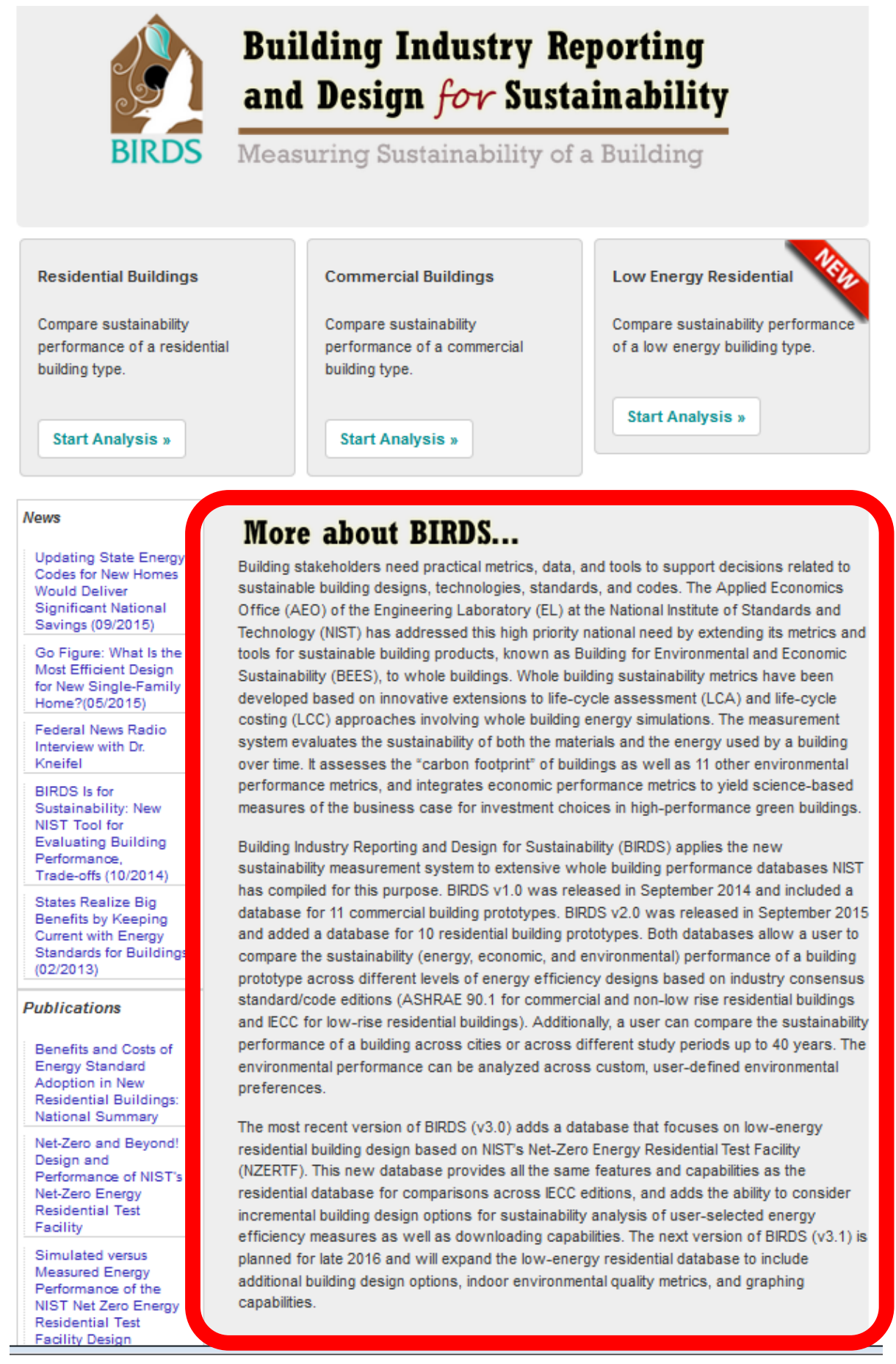

Figure 2-1 BIRDS Main Webpage - Introduction 
On the left hand side of the main page, a user can access information related to BIRDS, including recent news, related publications, and other related links (highlighted in Figure 2-2). Recent news will include news articles, press releases, and announcements related to BIRDS. The most recent and/or most downloaded BIRDS-related publications are shown, which a link to the NIST publication database to allow for a complete search of BIRDS publications. Related links include BIRDS's "sister software" - BEES - that allows for comparison of individual building products and the NIST Net Zero Energy Residential Test Facility (NZERTF) main page as well as access to the Applied Economics Office (AEO) and the Engineering Laboratory (EL) at NIST.

If the user is interested in additional information not available from the BIRDS main page or has comments to improve BIRDS, NIST can be contacted at either birds@ nist.gov or joshua.kneifel@nist.gov. 
Updating State Energy Codes for New Homes Would Deliver Significant National Savings (09/2015)

Go Figure: What is the Most Efficient Design for New Single-Family Home?(05/2015)

Federal News Radio Interview with Dr. Kneifel

BIRDS is for Sustainability: New NIST Tool for Evaluating Building Performance, Trade-offs (10/2014)

States Realize Big Benefits by Keeping Current with Energy Standards for Buildings (02/2013)

\section{Publications}

Benefits and Costs of Energy Standard Adoption in New Residential Buildings: National Summary

Net-Zero and Beyond! Design and Performance of NIST's Net-Zero Energy Residential Test Facility

Simulated versus Messured Energy Performance of the NIST Net Zero Energy Residential Test Facility Design

Sustainability Performance of the NIST Net Zero Energy Residential Test Facility Relative to a Maryland Code Compliant Design More.

\section{Related Links}

NIST NZERTF

BEES

Applied Economics Office

Engineering

Laboratory

\section{More about BIRDS..}

Building stakeholders need practical metrics, data, and tools to support decisions related to sustainable building designs, technologies, standards, and codes. The Applied Economics Office (AEO) of the Engineering Laboratory (EL) at the National Institute of Standards and Technology (NIST) has addressed this high priority national need by extending its metrics and tools for sustainable building products, known as Building for Environmental and Economic Sustainability (BEES), to whole buildings. Whole building sustainability metrics have been developed based on innovative extensions to life-cycle assessment (LCA) and life-cycle costing (LCC) approaches involving whole building energy simulations. The measurement system evaluates the sustainability of both the materials and the energy used by a building over time. It assesses the "carbon footprint" of buildings as well as 11 other environmental performance metrics, and integrates economic performance metrics to yield science-based measures of the business case for investment choices in high-performance green buildings.

Building Industry Reporting and Design for Sustainability (BIRDS) applies the new sustainability measurement system to extensive whole building performance databases NIST has compiled for this purpose. BIRDS v1.0 was released in September 2014 and included a database for 11 commercial building prototypes. BIRDS v2.0 was released in September 2015 and added a database for 10 residential building prototypes. Both databases allow a user to compare the sustainability (energy, economic, and environmental) performance of a building prototype across different levels of energy efficiency designs based on industry consensus standard/code editions (ASHRAE 90.1 for commercial and non-low rise residential buildings and IECC for low-rise residential buildings). Additionally, a user can compare the sustainability performance of a building across cities or across different study periods up to 40 years. The environmental performance can be analyzed across custom, user-defined environmental preferences.

The most recent version of BIRDS (v3.0) adds a database that focuses on low-energy residential building design based on NIST's Net-Zero Energy Residential Test Facility (NZERTF). This new database provides all the same features and capabilities as the residential database for comparisons across IECC editions, and adds the ability to consider incremental building design options for sustainability analysis of user-selected energy efficiency measures as well as downloading capabilities. The next version of BIRDS (v3.1) is planned for late 2016 and will expand the low-energy residential database to include additional building design options, indoor environmental quality metrics, and graphing capabilities.

\section{Figure 2-2 BIRDS Main Webpage - Related Links}

Above the introduction are links directing you to each of the BIRDS databases (highlighted in Figure 2-3). The Residential Buildings and Commercial Buildings "Start Analysis $>>$ " links 
direct you to the new residential database and new commercial buildings database, respectively. Each database allows for sustainability comparison across different building designs based on building energy codes/standards across different locations. The Low Energy Residential "Start Analysis $>>$ " link directs the user to the low-energy residential buildings web interface, which will allow a user to compare the sustainability performance of incremental changes in energy efficiency measures adopted in a single-family dwelling based on energy-efficiency measures incorporated into the NZERTF. The new database also allows for sustainability performance comparisons across multiple editions of the IECC (i.e. 2006, 2009, 2012, and 2015).

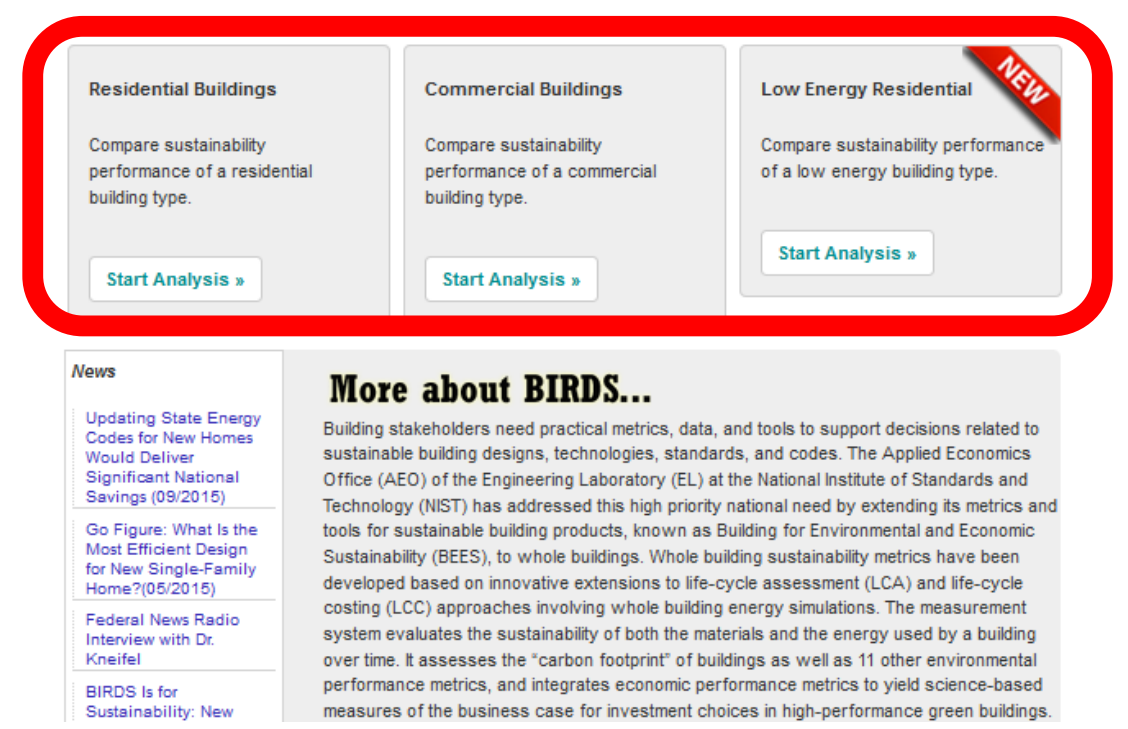

Figure 2-3 BIRDS Main Webpage - Database Links

For this tutorial, the user selects the Low E Residential "Start Analysis >>" link and is directed to the BIRDS New Low-Energy Residential database web interface (highlighted in Figure 2-4).
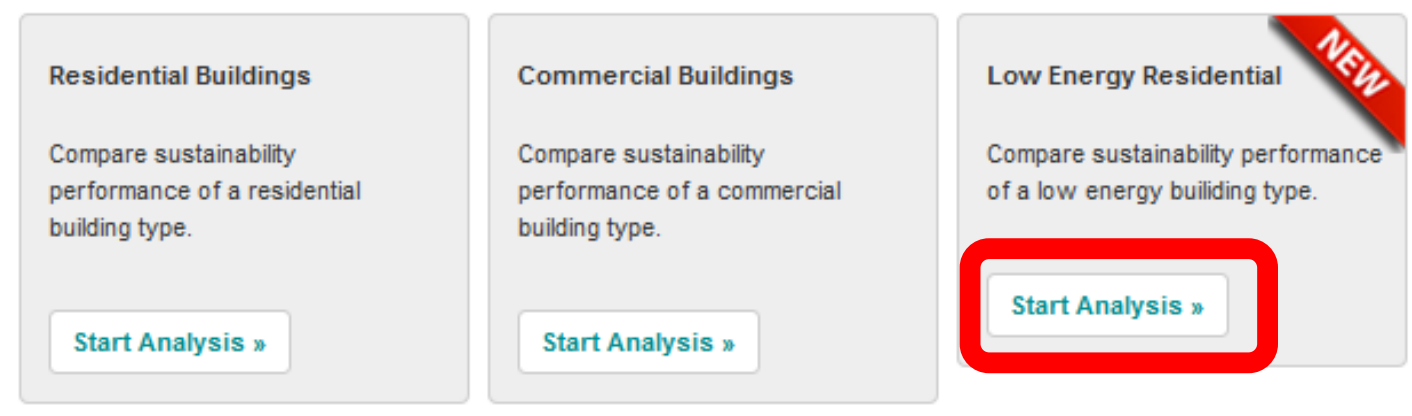

Figure 2-4 BIRDS Main Webpage - Start Analysis

The New Low-Energy Residential web interface defaults the user to Step 1 as shown in Figure 2-5. There are four steps in completing and viewing sustainability comparisons.

1. Select your general assumptions, location, and baseline building design. 
2. Select alternative building component properties to be compared to the baseline building design.

3. Select weighting preferences for environmental performance.

4. View results graph(s) and data.

At any step in the process, the user can access the BIRDS Home webpage, BIRDS New LowEnergy Residential database documentation, this tutorial, and FAQ at the top-right corner of the page as shown in Figure 2-5. Note that the successful computation of database results is contingent upon proper selection by the user of all parameters inputs. If any of the general assumptions, baseline building design components, alternative building component properties, and/or weighting preferences are not defined by the user at any point, no results will be displayed and input parameters that have not been defined or defined incorrectly will be noted in red text.

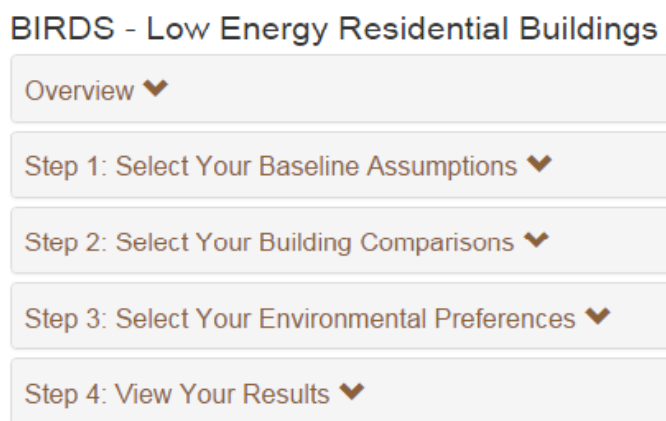

\section{Figure 2-5 BIRDS New Residential Interface - Initial View}

The remainder of this tutorial will walk the user through a detailed example and the resulting comparisons available to the user. Note that there are a variety of values that the user must select in order to view results, but BIRDS v3.0 includes further information (by clicking on the information icons noted later in the manual) and default values (where determined necessary) to assist a user in making those selections.

\subsection{Step 1: Selecting Your Baseline Assumptions}

The user completes the first part of "Step 1: Select Your Baseline Assumptions" by selecting the assumptions to be used in the analysis from the seven drop-down menus shown in Figure 2-6. Selections are made based on the preferences of the user. The user first selects the Building Type, which currently allows only for the selection of the NZERTF (based on the NIST NZERTF). For the second and the third assumptions, the user selects the State and City locations for the baseline building. These selections must be made sequentially. The only state and city options currently available are Maryland and Gaithersburg, respectively. The Discount Rate (the rate at which the user discounts future dollars) is the fourth assumption selected by the user. Two options are available: $\mathbf{3} \%$ and $\mathbf{8} \%$. Next, the user selects the assumed financing method using the Financing dropdown menu. Again, two options are available for 
selection: Cash Only and 80/20 (80 \% financing/20\% down payment). Construction Quality (e.g., architecture and finishes) is the sixth assumption selected by the user. He/she can choose either Average or Luxury construction quality (e.g., quality of interior finishes). Lastly, the user selects the length of the Study Period over which the analysis is conducted. Study period options range from 1 year to $\mathbf{4 0}$ years in one year increments. For further information on the assumptions, click the blue information icon next to "Select Analysis Assumptions".

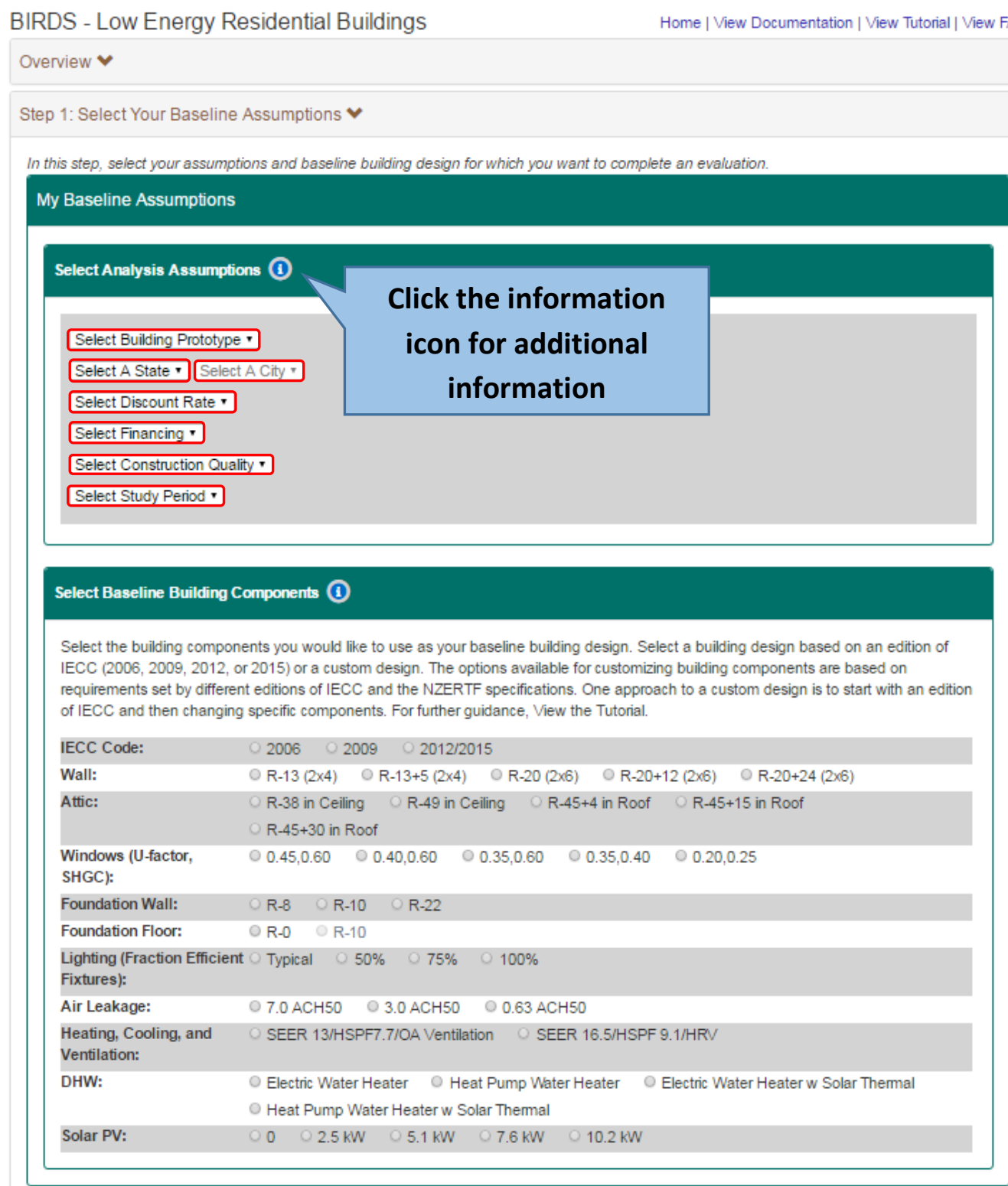

Figure 2-6 Baseline Assumptions - Analysis Assumptions 
In order to complete the second part of "Step 1: Select Your Baseline Assumptions", the components of the baseline building must be selected (Figure 2-7). The user has the option of either choosing a building design based on an edition of the International Energy Conservation Code (IECC) $(2006,2009,2012,2015)$ or a custom design. Note that the requirements for the assemblies selected for the baseline design are identical for both the 2012 IECC and 2015 IECC, and are combined for this version of BIRDS. Options available for building customization are based on the requirements of different editions of IECC and the NIST NZERTF specifications. These custom design options are categorized according to ten primary building components: Wall, Attic, Window, Foundation Wall, Foundation Floor, Lighting, Air Leakage, Heating, Cooling, and Ventilation (HVAC), Domestic Hot Water, and Solar photovoltaic. I-P units are displayed throughout BIRDS because the tool is designed for U.S.-related activities. As shown in Figure 2-7, five options are available for wall and attic insulation. There are also five options available for window specifications that are expressed in terms of U-Factor and Solar Heat Gain Coefficient (SHGC). Building foundation characteristics (Wall and Slab) are described in terms of insulation R-values. Three options are available for the Foundation Wall, while two are available for the Slab (Foundation Floor). Expressed as a fraction of efficient fixtures, four options are available for lighting. The four Air Leakage rates available are described in terms of air changes per hour at $50 \mathrm{~Pa}\left(\mathrm{ACH}_{50}\right)$. Two options are available for the baseline Heating, Cooling, and Ventilation system. The first is based on the federal minimum efficiency requirements. The other is based on the efficiency specifications of the system installed in the NIST NZERTF, which includes a separate dedicated outdoor air system with a heat recovery ventilator. The four options available for the Domestic Hot Water configuration are based on the federal minimum efficiency requirements and the specifications of the system installed in the NIST NZERTF, including the solar thermal system. Five options are available for the solar photovoltaic system, ranging from no solar photovoltaic system to a $10.2 \mathrm{~kW}$ system. For further details on the building components, click the information icon next to "Select Baseline Building Components". 
Click the information icon for additional information

Select Baseline Building Components (1)

Select the building components you would like to use as your baseline building design. Select a building design based on an edition of IECC $(2006,2009,2012$, or 2015) or a custom design. The options available for customizing building components are based on requirements set by different editions of IECC and the NZERTF specifications. One approach to a custom design is to start with an edition of IECC and then changing specific components. For further guidance, View the Tutorial.

\begin{tabular}{|c|c|}
\hline IECC Code: & $2006 \quad 2009 \quad 2012 / 2015$ \\
\hline Wall: & 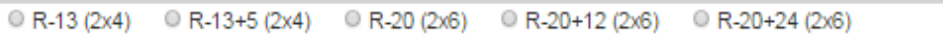 \\
\hline \multirow[t]{2}{*}{ Attic: } & R-38 in Ceiling R-49 in Ceiling R-45+4 in Roof R-45+15 in Roof \\
\hline & $R-45+30$ in Roof \\
\hline $\begin{array}{l}\text { Windows (U-factor, } \\
\text { SHGC): }\end{array}$ & $0.45,0.60 \bigcirc 0.40,0.60 \bigcirc 0.35,0.60 \bigcirc 0.35,0.40 \bigcirc 0.20,0.25$ \\
\hline Foundation Wall: & $\mathrm{R}-8$ R-10 R-22 \\
\hline Foundation Floor: & R-0 $\mathrm{R}-10$ \\
\hline $\begin{array}{l}\text { Lighting (Fraction Efficient } \\
\text { Fixtures): }\end{array}$ & Typical $50 \% \quad 75 \% \quad 100 \%$ \\
\hline Air Leakage: & $7.0 \mathrm{ACH} 50 \quad \bigcirc .0 \mathrm{ACH} 50 \bigcirc 0.63 \mathrm{ACH} 50$ \\
\hline $\begin{array}{l}\text { Heating, Cooling, and } \\
\text { Ventilation: }\end{array}$ & SEER 13/HSPF7.7/OA Ventilation SEER $16.5 / \mathrm{HSPF} 9.1 / \mathrm{HRV}$ \\
\hline \multirow[t]{2}{*}{ DHW: } & O Electric Water Heater Heat Pump Water Heater Electric Water Heater w Solar Thermal \\
\hline & O Heat Pump Water Heater w Solar Thermal \\
\hline Solar PV: & $0 \quad 2.5 \mathrm{~kW} \quad 5.1 \mathrm{~kW} \quad 7.6 \mathrm{~kW} \quad 10.2 \mathrm{~kW}$ \\
\hline
\end{tabular}

\section{Figure 2-7 Baseline Assumptions -Building Components}

If the user would like their baseline building to meet the specifications of an edition of the IECC, he/she must select their desired edition. The building component specifications associated with an IECC edition will automatically populate in the cells below following the selection of that edition (Figure 2-8). If the user would like to customize their baseline design, they can take one of two approaches: (1) manually select each of the 10 individual building components; or (2) select an edition of the IECC and manually change specific building components. 


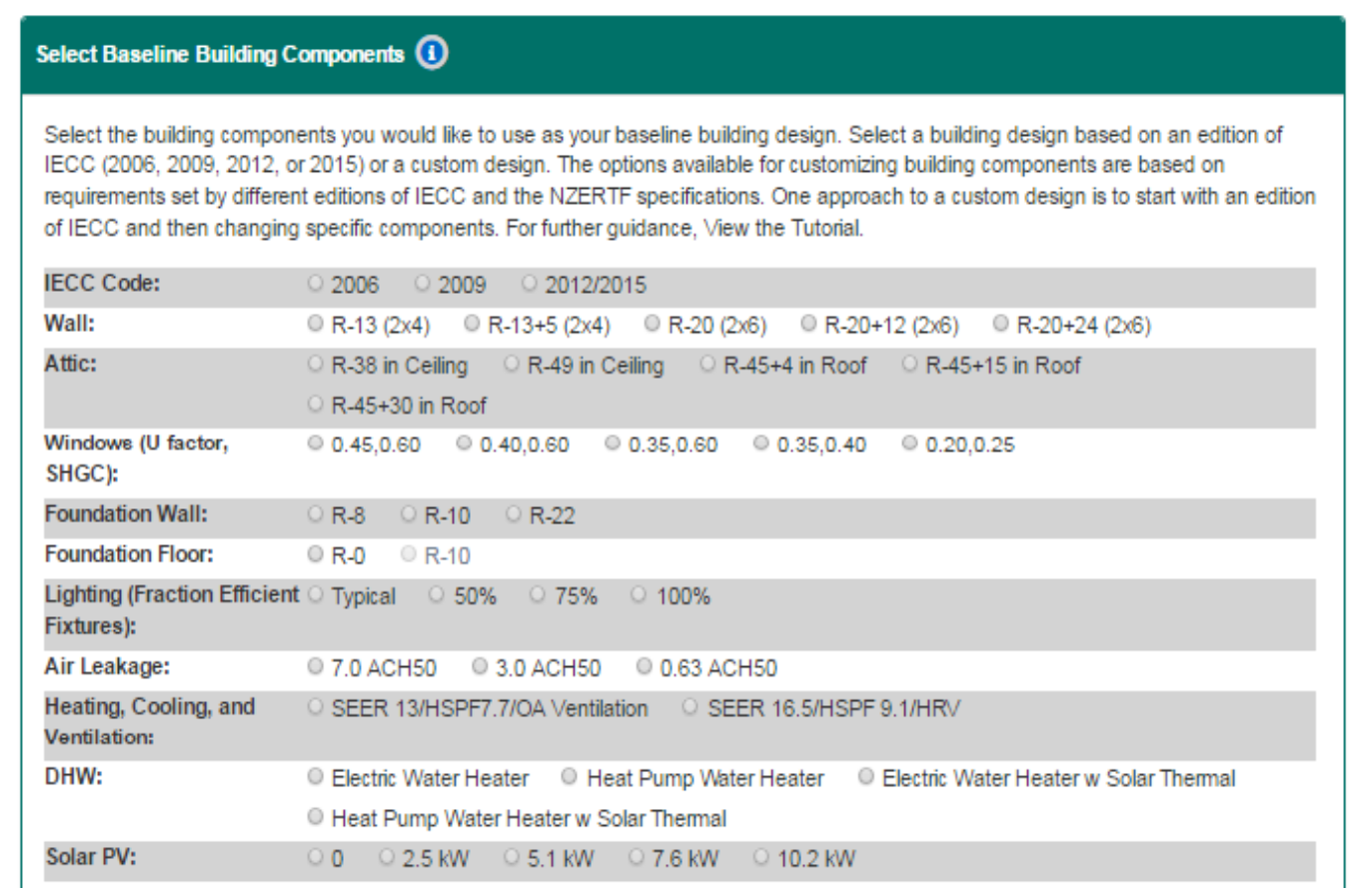

Figure 2-8 Building Component Specifications

For this tutorial, assume that the user is considering building a two-story home located in Gaithersburg, MD and constructed according to the specifications of the 2015 IECC as shown in Figure 2-9. The user assumes a $3 \%$ discount rate, full cash (Cash Only) financing, Average construction quality, and a 10-year study period. Notice that after selecting the NZERTF as the building type, a picture of the building and its characteristics are displayed to the right. The default selection for the building components is 2012/2015 IECC because the Maryland building code is comparable to the 2015 IECC as of March 23, 2016. Note that if an edition of the IECC is selected, blue text stating "Component Defaults associated with IECC Code," is displayed to the right of the IECC Code row. If a custom design is selected, red text stating, "User Defined Component Selection," will be displayed in the same location. Current state energy codes can be found at https://www.energycodes.gov/adoption/states. Following the selection of the above assumptions, the user selects the desired comparisons. 


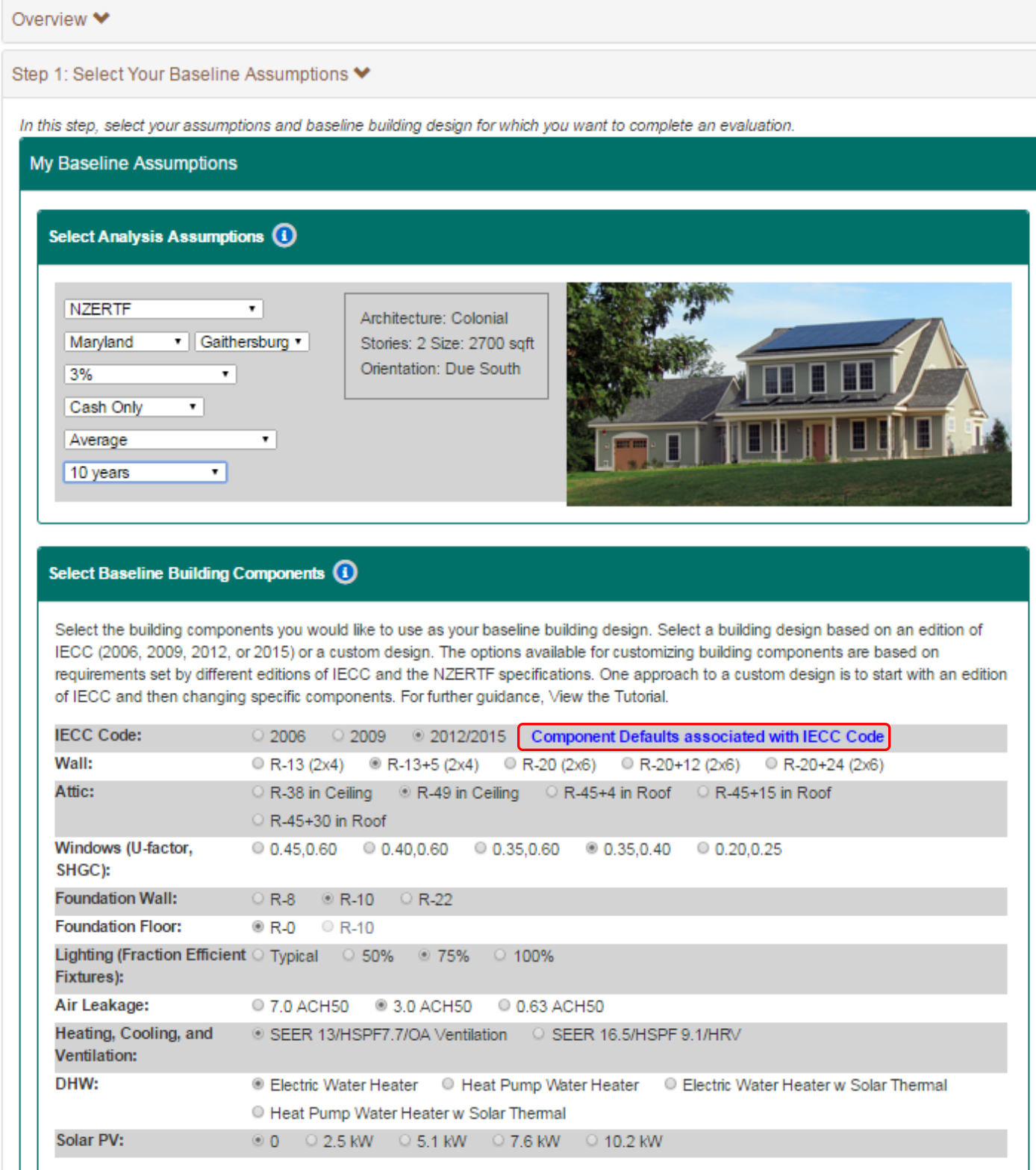

Figure 2-9 Baseline Building Details

\subsection{Step 2: Selecting Your Comparisons}

As shown in Figure 2-10, clicking on the "Step 2: Select Your Building Comparisons" tab displays two question prompts by which comparisons can be made (highlighted in red). The first question states, "Do you want to compare IECC editions?" The second question states, "Do you want to compare user-defined building alternatives?" The user has the option of selecting yes (Y) or no $(\mathbf{N})$ for either or both of the two questions. 


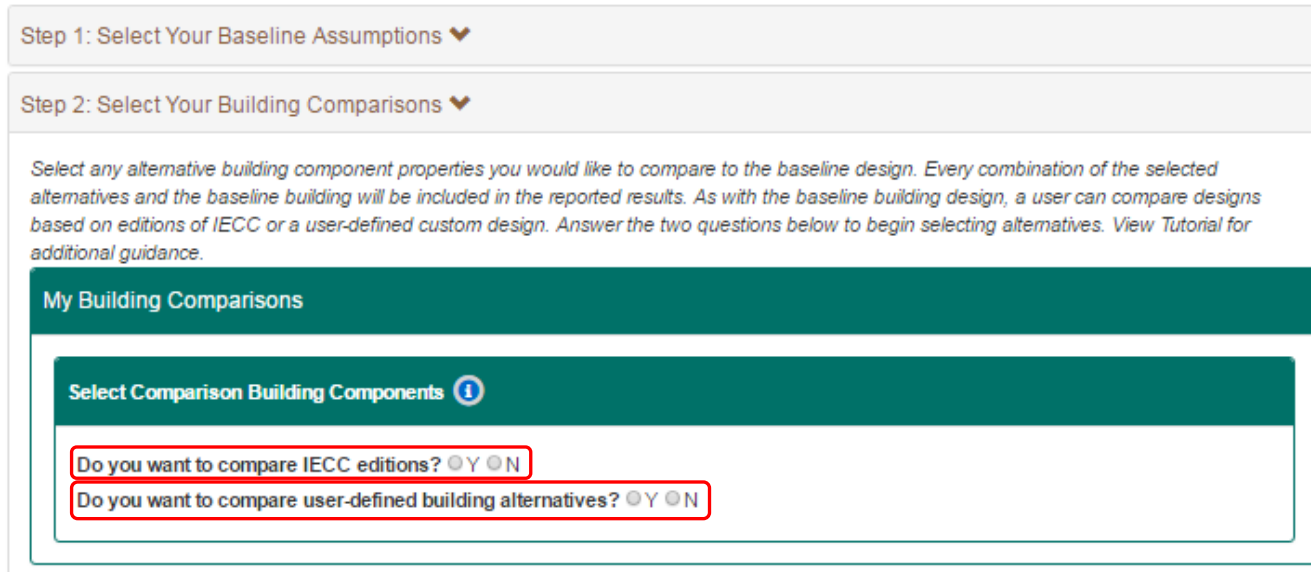

Figure 2-10 Selecting IECC Editions for Comparison

Should the user be interested in comparing across IECC editions, he/she must select "Y" for the first question and the IECC editions will appear below (Figure 2-11). The user will then select the alternative IECC edition(s) by checking the boxes corresponding to each. Note that if the assumed baseline building is constructed according to an IECC edition, that edition will not be available for selection. Since the baseline building in this tutorial uses 2015 IECC, it can no longer be selected as shown in Figure 2-11.

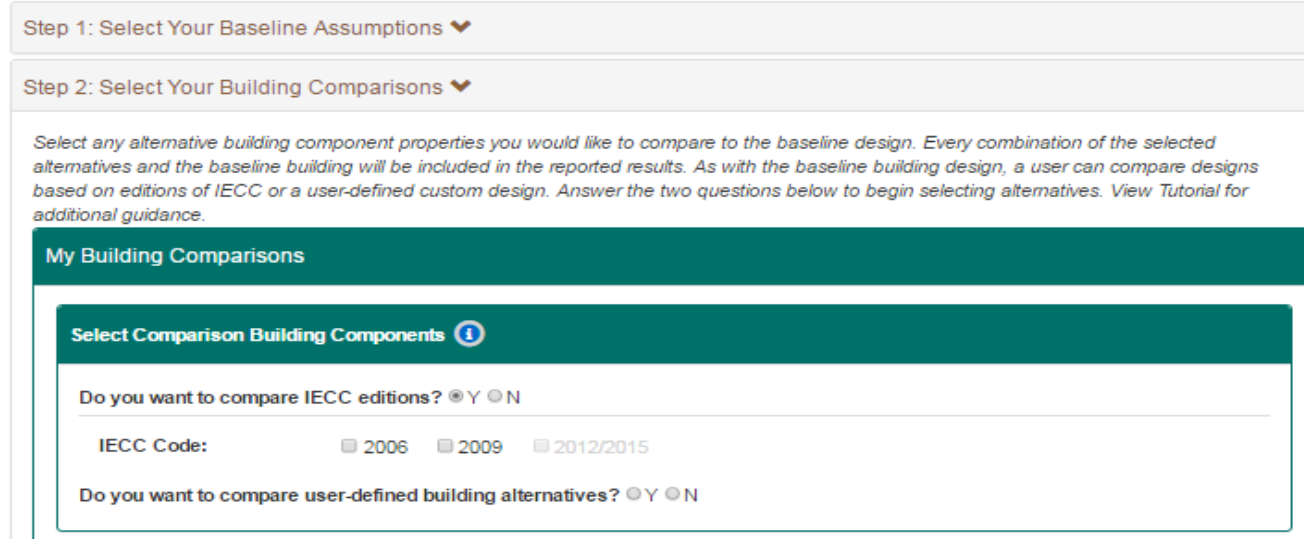

Figure 2-11 Comparison across IECC Editions

Should the user be interested in comparing a user-defined custom design to the baseline, he/she must select "Y" for the second prompt and the tab will expand, listing the options for the 10 major building components will appear (Figure 2-12). It is here that the user selects the building component alternatives. Note that all of the building component specifications associated with the baseline building can no longer be selected. The user has the option of comparing their baseline design to alternative editions AND user-defined custom designs, which could include up to the entire set of 240000 building design options. "Y" must be selected for both prompts. In 
this case, the alternative building components defined in all selected IECC editions will have automatically been selected. Each combination of the baseline building and the alternative selections will be available for analysis in Step 4. The information icon next to "Select Building Comparison Components" includes information on each of the 10 building components.

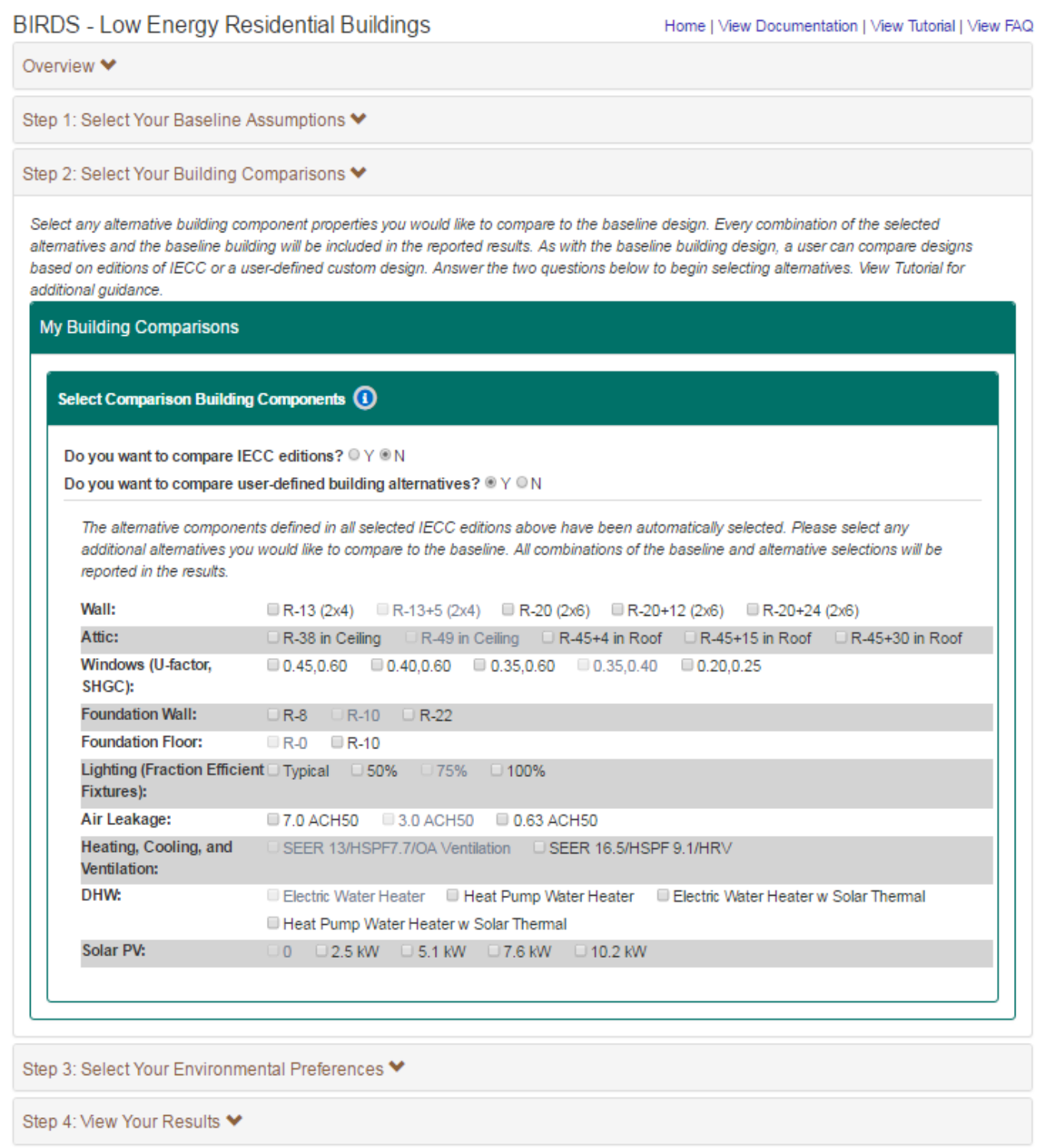

\section{Figure 2-12 Selecting User-Defined Building Alternatives for Comparison}

For this tutorial, assume that the user is solely interested in evaluating the impacts of improving the thermal integrity of the baseline building's wall assembly by switching to advanced framing (2x6 wall assembly) and increasing wall insulation levels (R-20, R-20+12, and R-20+24). To do this, the user would check the boxes to the right of R-13+5 (2x4) (Figure 2-13). 


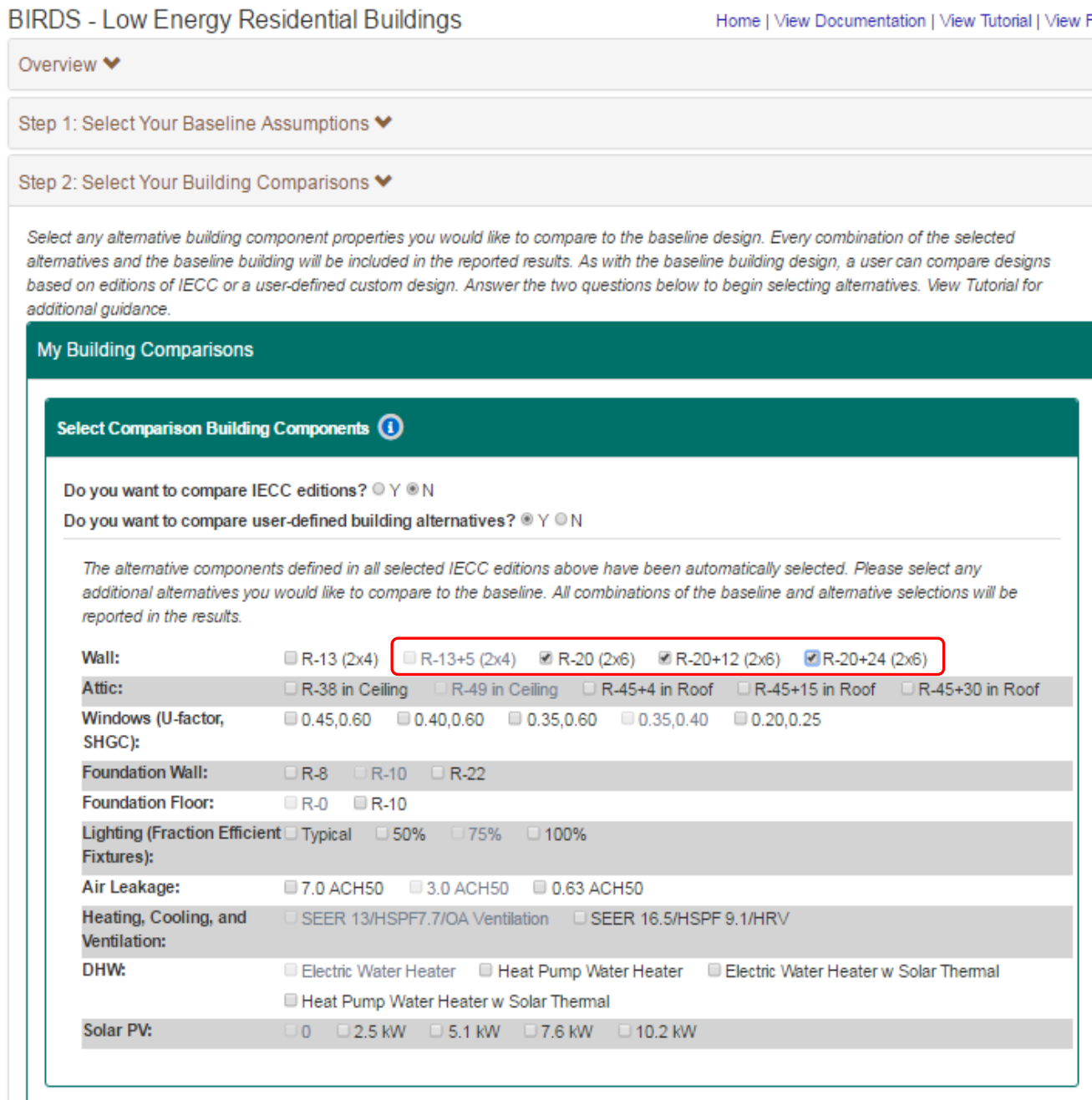

Step 3: Select Your Environmental Preferences $\vee$

Step 4: View Your Results $\checkmark$

\section{Figure 2-13 Selected Design Alternative to be compared to the Baseline}

\subsection{Step 3: Selecting Environmental Weighting Preferences}

Clicking on the "Step 3: Select Your Environmental Preferences" displays an introductory paragraph that describes how the 12 environmental impact categories are used to compute the Environmental Impact Score (EIS). For further explanation of each of the environmental impact categories, please click on the information icon in the text. The user must define their preferences regarding the relative importance of each environmental impact. They can either select one of the pre-defined weight sets or create their own. If using a pre-defined weight set, the user must start by selecting their Environmental Weighting Approach from the dropdown menu, which includes 4 pre-defined options as shown in Figure 2-14 (highlighted in red). The user can view the weights for each of the four pre-defined approaches on the right-hand side of 
the screen. For information on the environmental weighting approach or pre-defined weight sets, click the appropriate information icons.

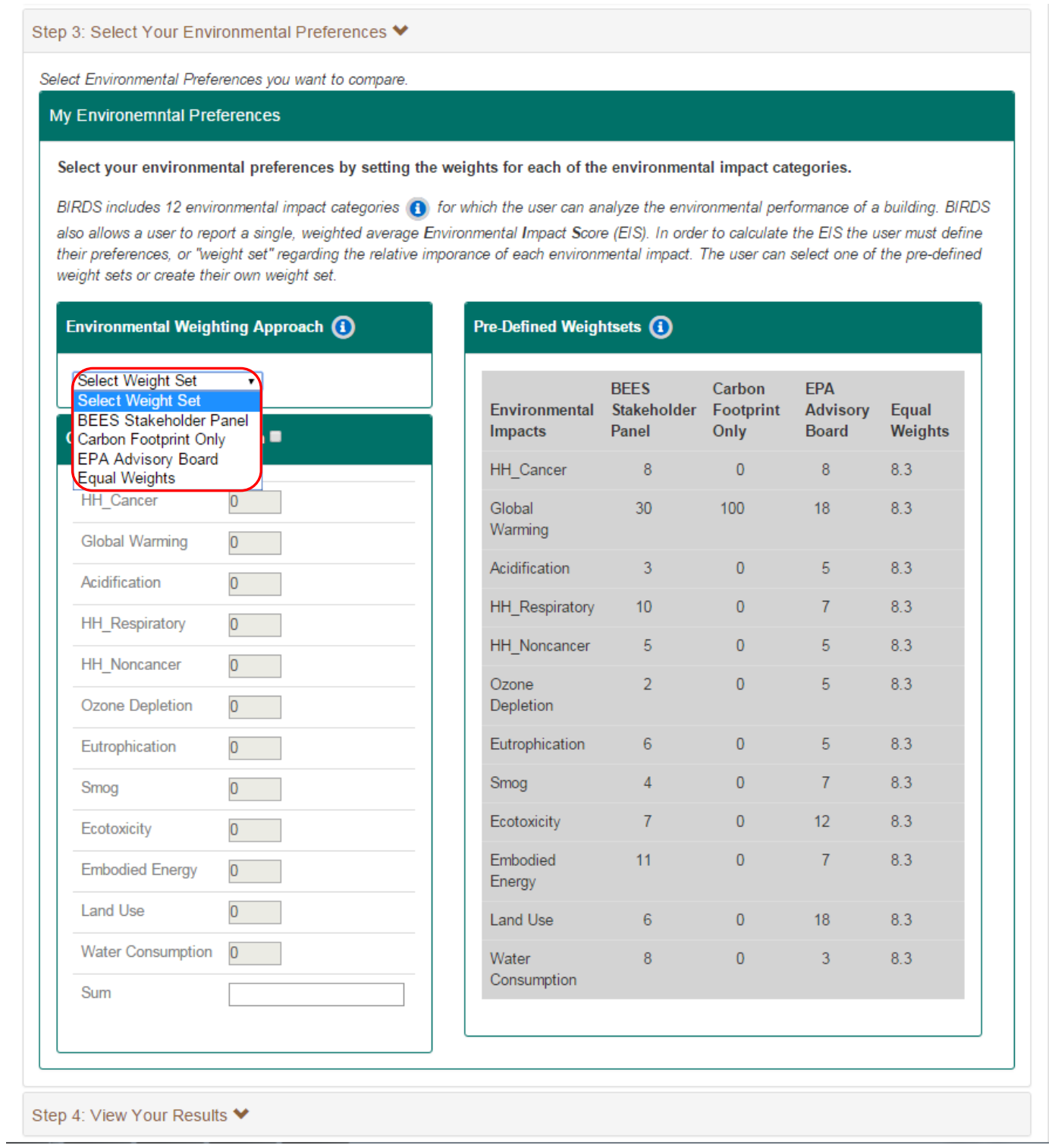

Figure 2-14 Selecting Environmental Weighting Preferences - Pre-defined Weighting Approach

Should the user choose to create their own series of weights, they must check the "Create Weighting Approach" box. They will then assign a weight ranging from 0 to 100 to each of the 12 impact categories. The sum of the weights must total 100. For this tutorial, assume that only four environmental impacts are important to the user (Global Warming, Acidification (i.e. acid rain), Ozone Depletion, and Water Consumption) and choose to place an equal weight on these categories (25\%) while ignoring the other impacts. He/she will check the "Create Weighting 
Approach" box, and assign a weight of 25 to these categories (Figure 2-15). Once the My Weights approach has been created, it can be selected in the drop down menu.

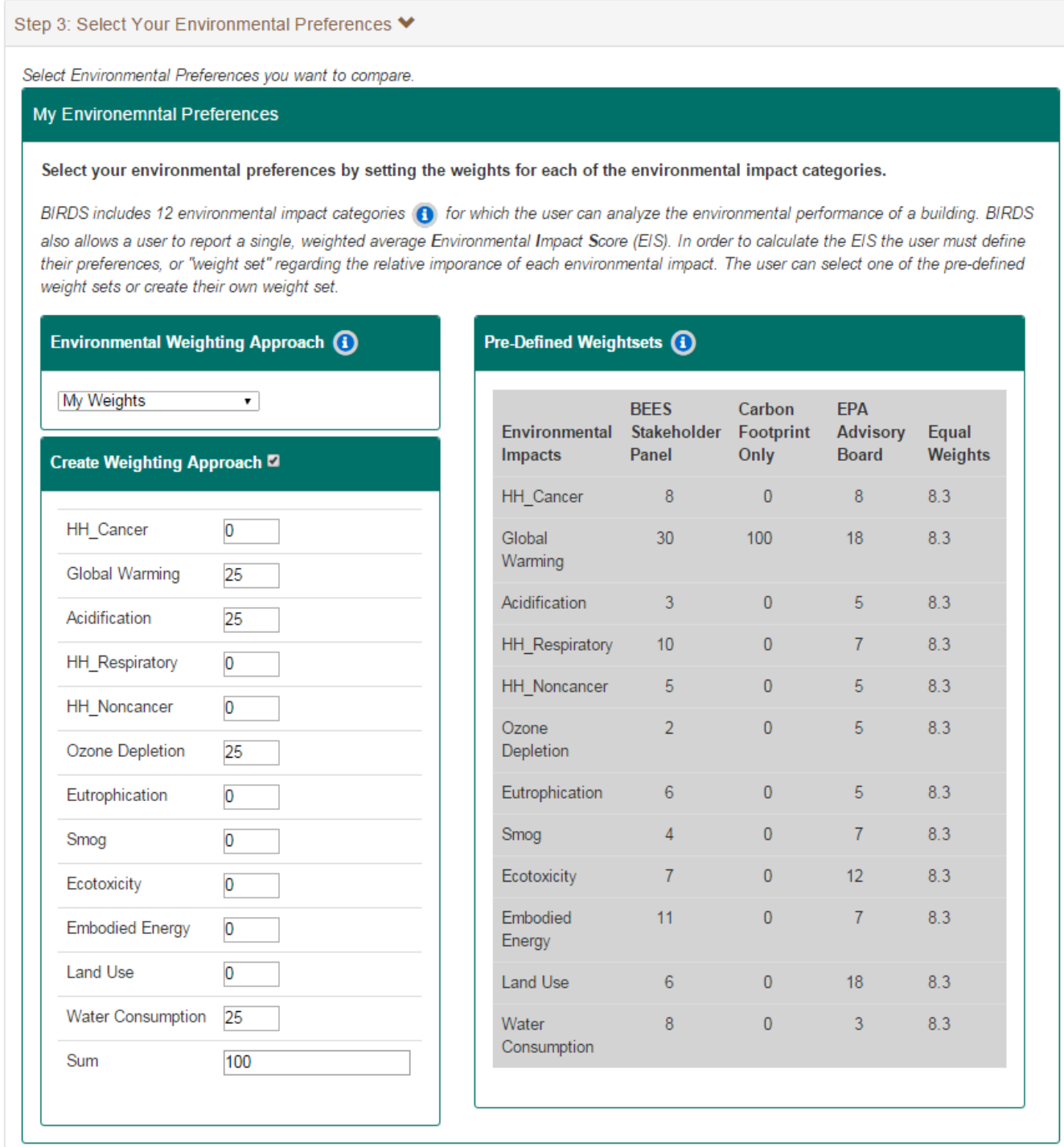

Step 4: View Your Results $\checkmark$

\section{Figure 2-15 Selecting Environmental Weighting Preferences - Custom Weighting}

Successful computation of database results is contingent on the proper selection of all the inputs discussed up to this point. If any of the general assumptions, baseline building design components, building component properties, and/or weighting preferences are not defined by the user at any point, no results will be displayed and any incorrect input parameters will be noted in red text. 


\subsection{Step 4: Viewing Results}

Clicking on the "Step 4: View Results" tab will display the "Select Chart Options" section. Three different chart types are available in the application: Life-Cycle Cost, Operating Energy, or Environmental Impact. As shown in Figure 2-16, the user must first "Select Chart Type" from the dropdown menu, then the "Building Component for Comparison" for the comparison to be made, and the "Units" in which the user prefers the results. Note that the units include a per unit of floor area impact, which is only reported in square feet $\left(\mathrm{ft}^{2}\right)$ within BIRDS and not square meters because the tool is designed for use in the United States. For additional information, a user can click on the information icons. Once the user has made these selections, the user presses the "View" button to see the results, at which point the results graph with its corresponding data table will be displayed.

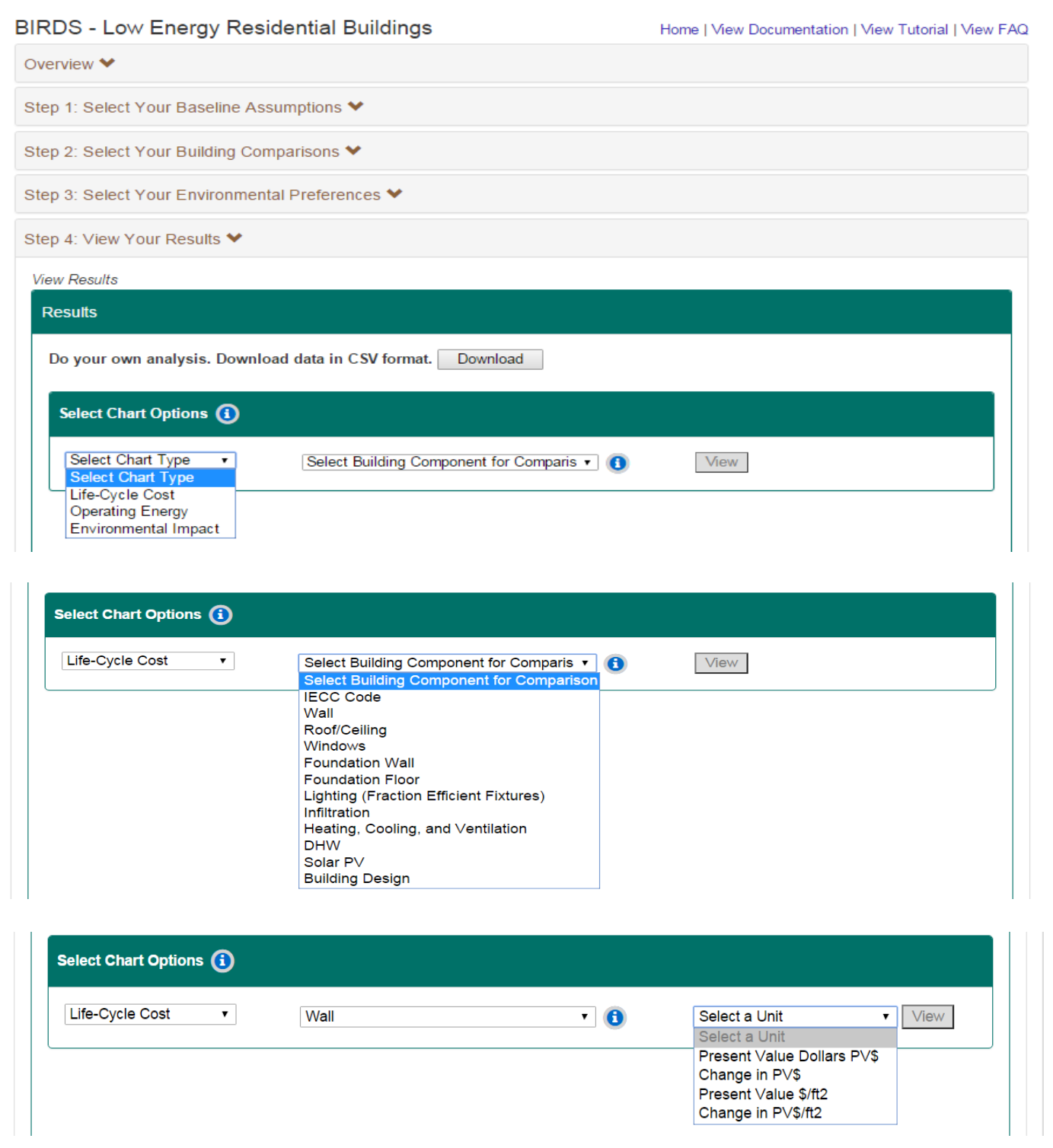

Figure 2-16 Selecting Chart Options 
Unlike the previous versions of BIRDS, BIRDS v3.0 now allows users to download data in CSV format (BIRDSRawData.txt) for the purpose of conducting their own analysis that cannot currently be displayed in BIRDS's graphing features. The user can download the data by clicking the "Download" button (Figure 2-17). Units for the variables reported in the BIRDSRawData.txt file can be found in the BIRDS v3.0 Technical Manual.

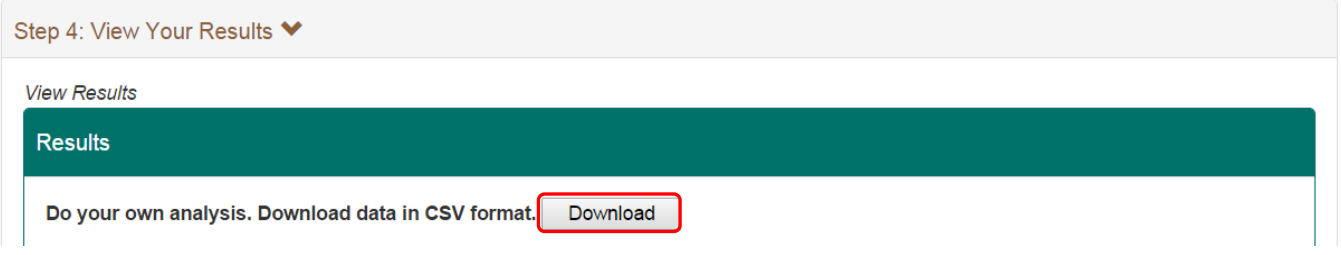

Figure 2-17 Downloading Data

Assume that the first comparison the user would like to view is the life-cycle costs of the baseline building design as the wall assembly is changed. Figure 2-18 shows the Life-Cycle Cost results with a graph of the total life-cycle costs per $\mathrm{ft}^{2}$ in present value dollars (PV\$) for the baseline and the three design alternatives given a 10-year study period. As can be seen in the graph, total present value life-cycle costs per unit of floor area vary from $\$ 5.81 / \mathrm{m}^{2}\left(\$ 62.40 / \mathrm{ft}^{2}\right)$ to $\$ 5.86 / \mathrm{m}^{2}\left(\$ 63.10 / \mathrm{ft}^{2}\right)$. Switching from R-13+5 (2x4) to an R-20 (2x6) wall assembly has relatively no impact on costs per $\mathrm{ft}^{2}$. Only in the cases where the additional rigid insulation is added are there noticeable changes (an increase) in the life-cycle costs per unit of floor area. 

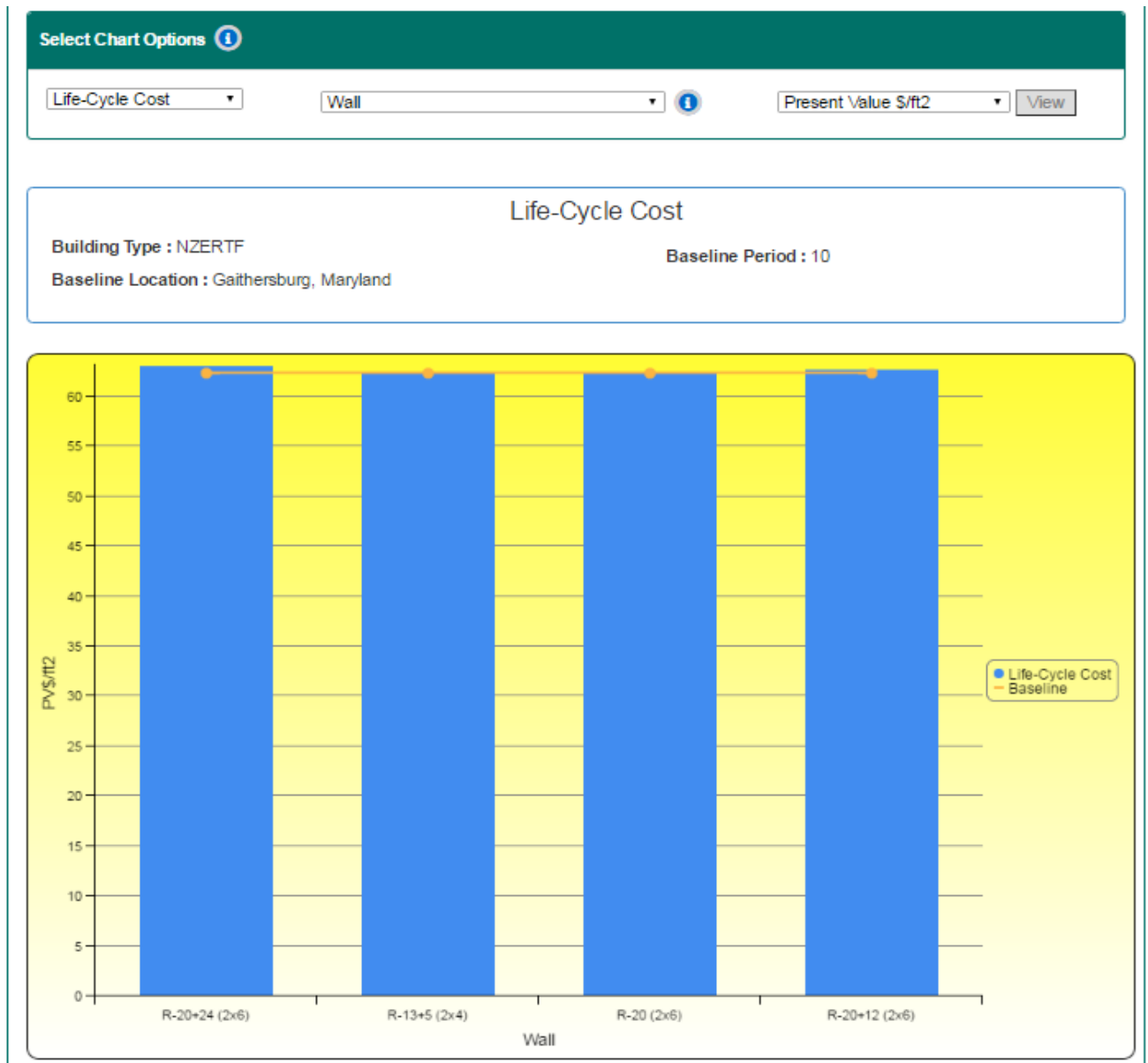

\begin{tabular}{|c|c|c|c|c|c|}
\hline Life-Cycle Cost & Unit & $R-20+24(2 \times 6)$ & $R-13+5(2 \times 4)$ & $R-20(2 \times 6)$ & $R-20+12(2 \times 6)$ \\
\hline Total & Present Value Dollars PVS & 170,427 & 168,459 & 168,502 & 169,280 \\
\hline Change from Baseline & Change in PVS & 1,968 & 0 & 43 & 821 \\
\hline Total & Present Value S/ft2 & 63.1 & 62.4 & 62.4 & 62.7 \\
\hline Change from Baseline & Change in PV/S/ft2 & 0.7 & 0 & 0 & 0.3 \\
\hline Change from Baseline & $\%$ & 1.2 & 0 & 0.0 & 0.5 \\
\hline
\end{tabular}

\section{Figure 2-18 Life-Cycle Cost Graph by Wall Assembly for Baseline Assumptions}

A user can interact with the graph by scrolling over and viewing the value of each data point.

The data table displayed below the graph is more comprehensive, and includes all of the possible metrics available for comparisons across wall assemblies given the baseline assumptions. The table includes total life-cycle costs, change in life-cycle costs relative to the baseline, total lifecycle costs per $\mathrm{ft}^{2}$, change in life-cycle cost per $\mathrm{ft}^{2}$ relative to the baseline, and percentage change in life-cycle costs relative to the baseline.

The next series of steps are followed to evaluate the impacts of wall assembly structure changes on energy use. By changing the chart type from Life-Cycle Cost to Operating Energy, keeping Wall as the building component for comparison, selecting Change in $\mathbf{k W h}$ as the unit of 
measure and clicking "View", the user can now observe the total changes in annual energy use (in $\mathrm{kWh}$ ) across the four selected wall component alternatives (Figure 2-19) relative to the baseline (R-13+5 (2x4)). Because all building designs are being compared to the baseline, the change in energy consumption is 0 (zero) for the baseline design. Switching from the baseline to an R-20 (2x6) wall assembly leads to only a minimal increases in total energy use of $255 \mathrm{kWh}$ over 10 years. Although the wall assembly structures have changed between the baseline and the alternative, the overall thermal integrity of the wall has slightly declined, resulting in a slight increase in consumption. On the other hand, use of either R-12 or R-24 rigid insulation in addition to the R-20 batt insulation significantly improves the overall thermal resistance of the walls, reducing total energy use by roughly $4.9 \%(11550 \mathrm{kWh})$ and $6.8 \%(16092 \mathrm{kWh})$, respectively. Again, a more comprehensive data table can be found below the graph. 


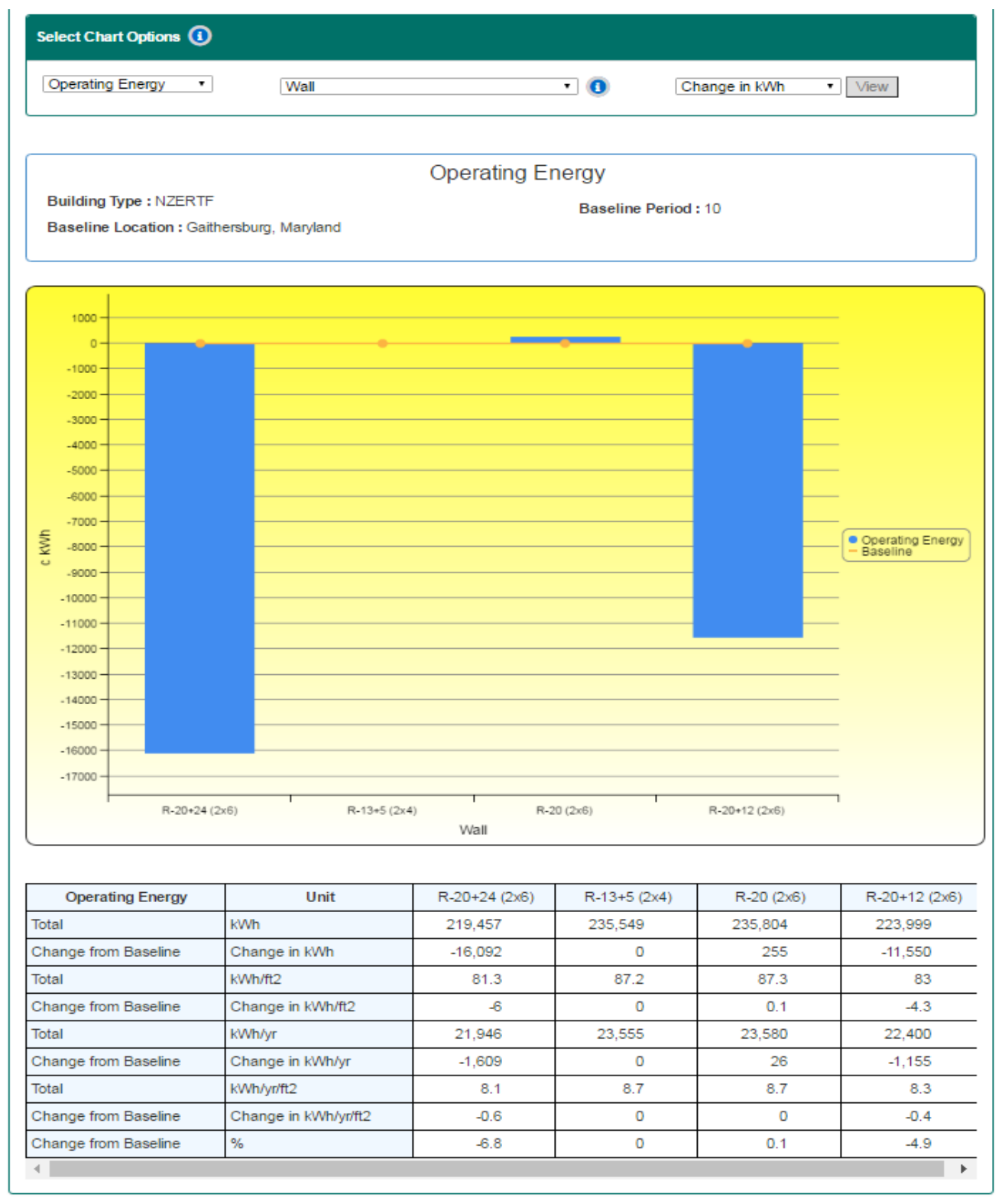

Figure 2-19 Operating Energy Graph by Wall Assembly for Baseline Assumptions

If the user is interested in seeing how the different building designs impact the life-cycle environmental performance of the house, he/she must make an additional selection, the environmental impact category, which can be either a single impact category or the weighted average impact (Environmental Impact Score - EIS) based on the weighting approach selected in Step 3 (My Weights). In this case, assume that the user wishes to view the Environmental Impact Score. By selecting Environmental Impact - All (weighted) - Environmental Impact 
Score, the user sees the results in Figure 2-20, which shows that the R-20+12 wall assembly leads to the lowest EIS (6.369). ${ }^{2}$
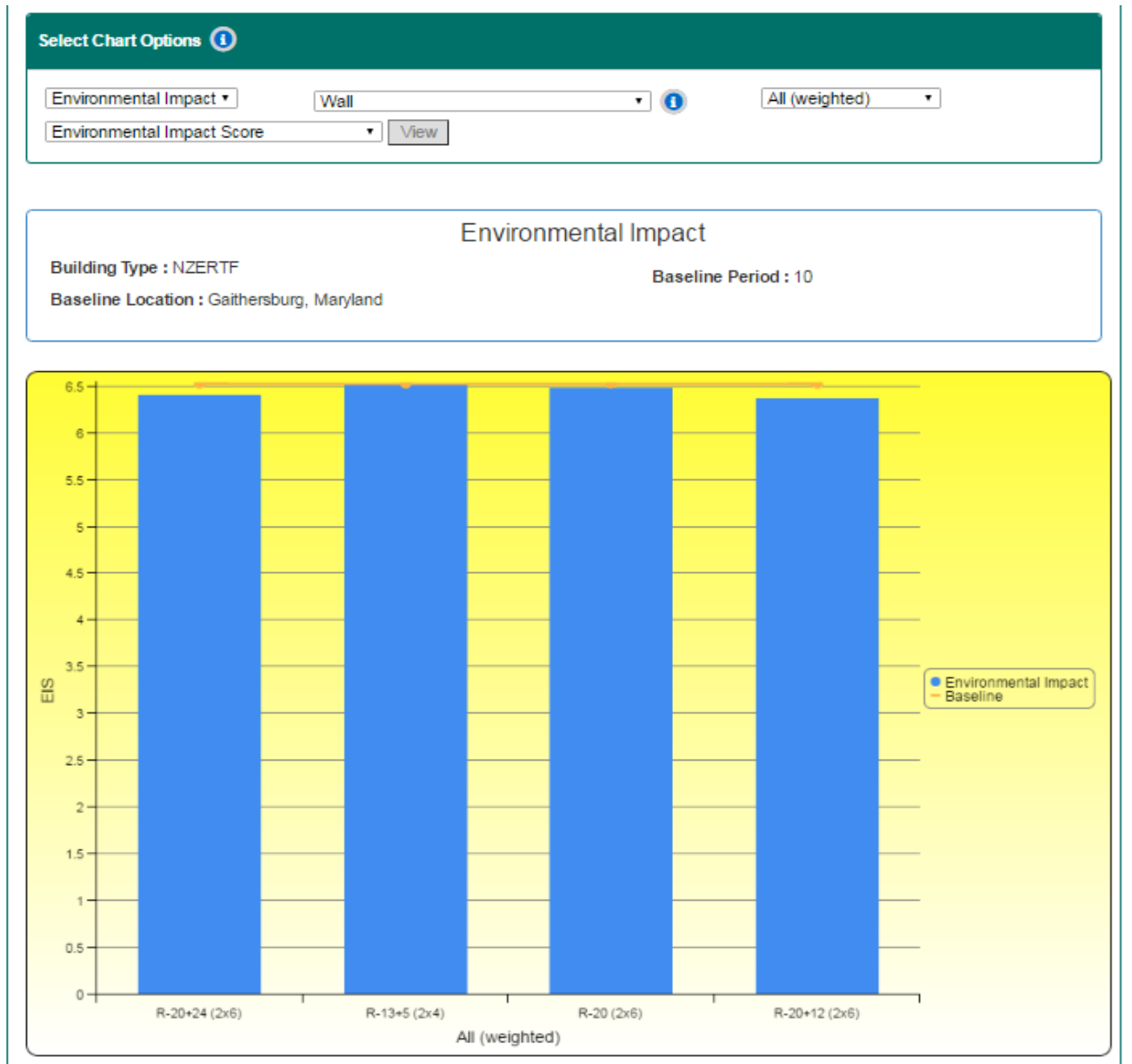

\begin{tabular}{|c|c|c|c|c|c|}
\hline Environmental Impact & Unit & $\mathrm{R}-20+24(2 \times 6)$ & $\mathrm{R}-13+5(2 \times 4)$ & $R-20(2 \times 6)$ & $\mathrm{R}-20+12(2 \times 6)$ \\
\hline Total & Environmental Impact Score & 6.408 & 6.529 & 6.48 & 6.369 \\
\hline Change from Baseline & Change in Environmental Impact Score & -0.12 & 0.001 & -0.048 & -0.159 \\
\hline Total & Environmental Impact Score/ft2 & 0.002 & 0.002 & 0.002 & 0.002 \\
\hline Change from Baseline & Change in Environmental Impact Score/ft2 & 0 & 0 & 0 & 0 \\
\hline Change from Baseline & $\%$ & -1.8 & 0.0 & -0.7 & -2.4 \\
\hline
\end{tabular}

Figure 2-20 Environmental Impact Score by Wall Assembly - for Baseline

The user can also view each individual environmental impact category result. For example, Figure 2-21 shows a graph of the total Global Warming Potential impacts in kilograms of carbon dioxide equivalent $\left(\mathrm{CO}_{2} \mathrm{e}\right)$ emissions. Switching to an $\mathbf{R - 2 0 + 2 4}$ wall assembly has the

\footnotetext{
${ }^{2}$ Note that the EIS is an aggregate measure to allow for relative comparisons across building designs based on a user's environmental preferences, and is only useful when comparing designs using the same weighting approach. Therefore, the magnitude of a single EIS cannot be interpreted on its own.
} 
highest impact on global warming potential, with a decrease of $3213.16 \mathrm{~kg}$ of $\mathrm{CO}_{2} \mathrm{e}$ relative to the 2015 IECC design.
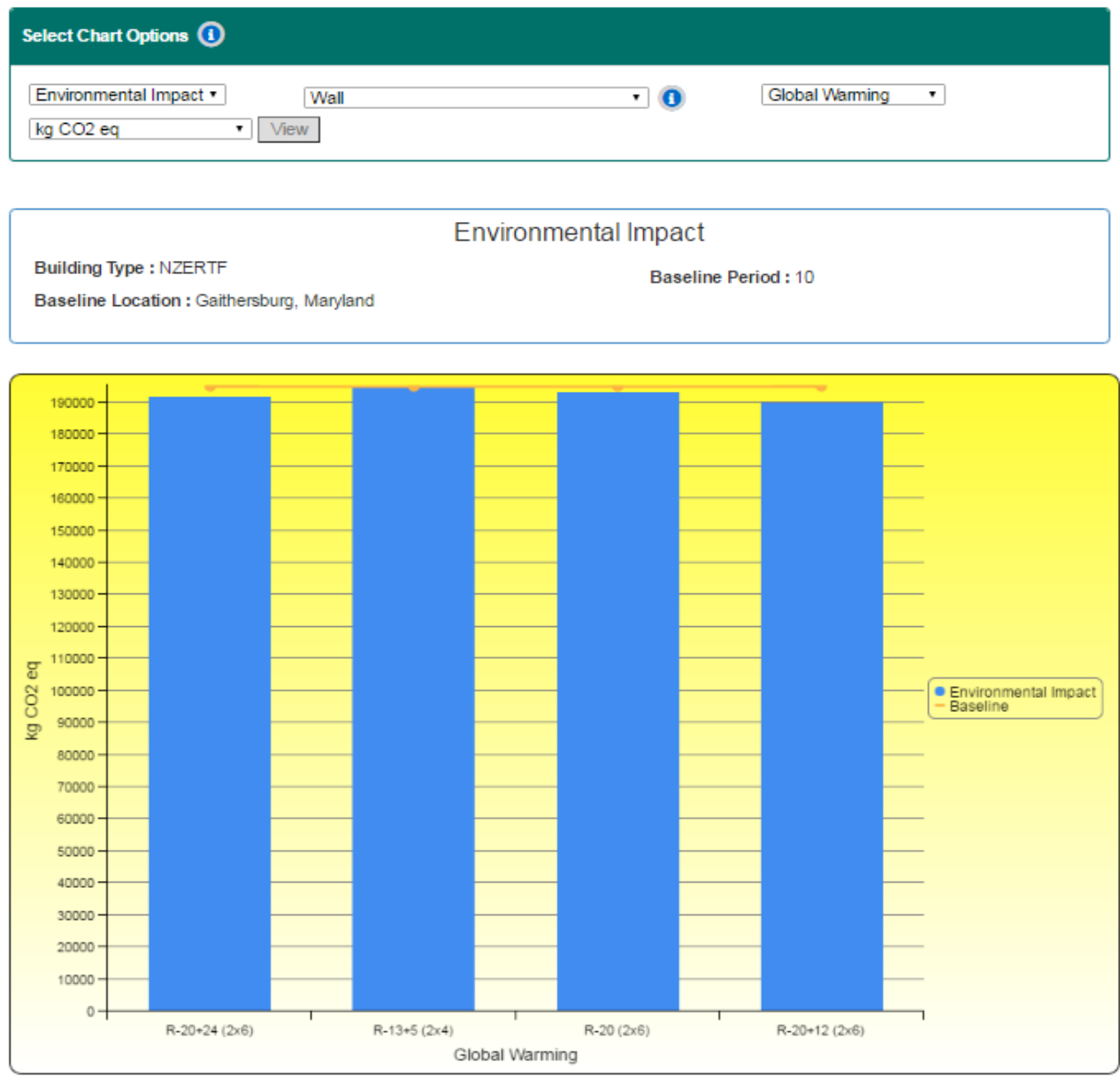

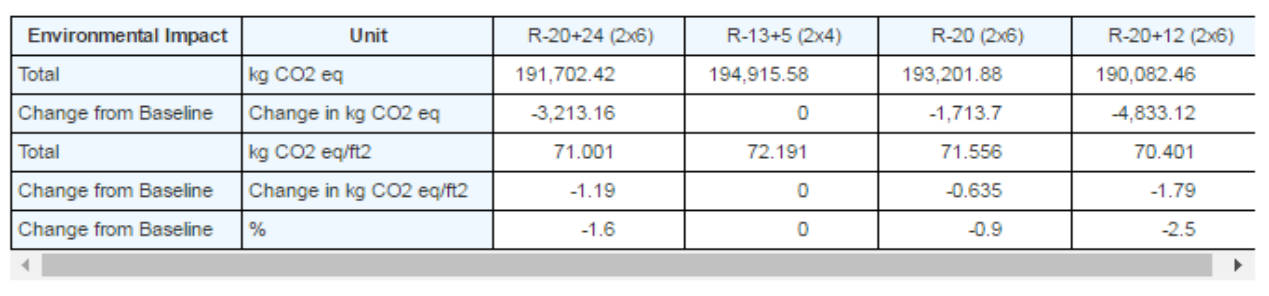

Figure 2-21 Global Warming Potential by Wall Assembly Structure - for Baseline Assumptions 


\section{Summary}

This tutorial guides the user through a detailed example of analysis that can be completed using the BIRDS new low-energy residential database web interface. The energy, environmental, and economic performance of a wood-framed, single-family dwelling based on the NIST NZERTF was compared across a number of factors. The life-cycle costs of the baseline building design (constructed to meet the 2015 IECC requirements) were compared to three similar alternative designs, each with a different wall assembly structure than the baseline. Assuming a 10-year study period, life-cycle costs per unit of floor area $\left(\mathrm{ft}^{2}\right)$ increase as the baseline wall assembly removes the rigid insulation and replaces the R-13 batt insulation for R-20 in the wall cavity and advanced framing is used. Life-cycle costs increase even further as the additional batt insulation is paired with additional rigid insulation. Relative to the baseline building, annual energy consumption increases slightly when the baseline wall assembly structure switches from

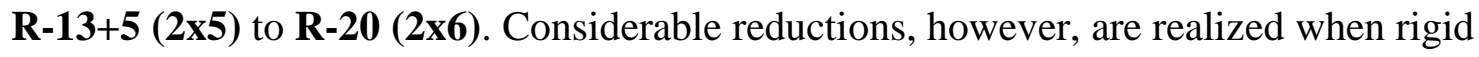
insulation is paired together with the $\mathbf{R - 2 0}$ (2x6) wall assembly. The reductions in energy consumption translate to reductions in Global Warming Potential (i.e. carbon emissions). Its impact on the Environmental Impact Score, however, is a bit ambiguous due to the weights selected for this tutorial.

These are just a few of the comparisons the user could make with BIRDS v3.0. A user can compare any or all of the 240000 building designs across the different general analysis assumptions, including varying discount rates, financing options, construction qualities, and study periods, to determine which designs are optimal for their sustainability goals. The user's goals could be focused solely on reducing operating energy consumption, savings money, or on reducing a specific environmental impact (e.g., Global Warming Potential). A user could also use a combination of these results (e.g., Environmental Impact Score - EIS) as factors in their decision-making process. Many of these comparisons are available within the BIRDS interface, but the ability to download the selected results also gives the user flexibility in analyzing the data however best fits their needs regardless of the current graphing features within BIRDS.

Future versions of BIRDS will expand on these general analysis assumptions to give the user even greater customization. A high priority has been placed on incorporation of additional locations and building prototypes as well as additional options for the parameters that already have two or more options available. In addition to new assumption options, additional building component options will be included in future versions of BIRDS, including brick wall construction and gas space and water heating. The results options will be expanded to include indoor environmental quality and additional life-cycle cost metrics, and new graphing features to allow more complex comparisons, such as scatterplots of all selected building designs.

The associated documentation (Kneifel et al. 2016) for the BIRDS new Low-Energy Residential database will assist with any questions related to the underlying definitions, assumptions, data sources, and methodology. Future versions of BIRDS will update current databases with 
additional energy code editions and a more extensive database that includes additional lowenergy residential building types. Please feel free to give your feedback on issues with BIRDS, information on how you use BIRDS, and/or what additional features you would like to have in future versions of BIRDS by sending an email to birds@ nist.gov. 


\section{References}

Brundtland Commission (1987). Our Common Future: Report of the World Commission on Environment and Development. UN Documents Gatheringa Body of Global Agreements.

International Code Council (ICC) (2009). 2009 International Energy Conservation Code. Washington, DC, International Code Council.

International Code Council (ICC) (2012). 2012 International Energy Conservation Code. Washington, DC, International Code Council.

International Code Council (ICC) (2015). 2015 International Energy Conservation Code. Washington, DC, International Code Council.

International Code Council (ICC) Inc. (2006). 2006 International Energy Conservation Code.

Kneifel, J. and P. Lavappa (2015). "Building Industry Reporting and Design for Sustainability (BIRDS) New Residential Database Technical Manual." NIST Technical Note 1878.

Kneifel, J., Lavappa, P., O'Rear, E., Greig, A., Suh, S. (2016) " Building Industry Reporting and Design for Sustainability (BIRDS) Low-Energy Residential Database Technical Manual." NIST Technical Note XXXX.

Lippiatt, B., et al. (2013). Building Industry Reporting and Design for Sustainability (BIRDS) Technical Manual and User Guide, NIST TN 1814. National Institute of Standards and Technology. Gaithersburg, MD.

National Institute of Standards and Technology (NIST) (2010). Building for Environmental and Economic Sustainability (BEES) Online Software, Applied Economics Office, Engineering Laboratory.

National Institute of Standards and Technology (NIST) (2014). Building Industry Reporting and Design for Sustainability (BIRDS) v1.0 Web Interface, Applied Economics Office, Engineering Laboratory. 